Korean - English obstruent mapping in non-CV positions

\title{
Perceptual category mapping between English and Korean obstruents in non-CV positions: Prosodic location effects in second language identification skills.
}

Hanyong Park (Department of Linguistics, University of Wisconsin-Milwaukee) and

Kenneth J. de Jong (Department of Linguistics, Indiana University, Bloomington)

Corresponding author: H. Park. Department of Linguistics, University of Wisconsin-

Milwaukee, Johnston Hall 123, P.O. Box 413, Milwaukee, Wisconsin 53201-0413. Tel.:

$+14142296166$

Email:park27@uwm.edu

(C) 2017. This manuscript version is made available under the Elsevier user license http://www.elsevier.com/open-access/userlicense/1.0/ 


\begin{abstract}
This study examines the degree to which mapping patterns between native language (L1) and second language (L2) categories for one prosodic context will generalize to other prosodic contexts, and how position-specific neutralization in the L1 influences the category mappings. Forty L1-Korean learners of English listened to English nonsense words consisting of $/ \mathrm{p} \mathrm{b} \mathrm{tdfv} \theta \partial /$ and /a/, with the consonants appearing in pre-stressed intervocalic, post-stressed intervocalic, or coda context, and were asked to identify the consonant with both Korean and English labeling and to give gradient evaluations of the goodness of each label to the stimuli. Results show that the mapping patterns differ extensively from those found previously with the same subjects for consonants in initial, onset context. The mapping patterns for the intervocalic context also differed by position with respect to stress location. Coda consonants elicited poor goodness-of-fit and noisier mapping patterns for all segments, suggesting that an L1 coda neutralization process put all L2-English sounds in codas as "new" sounds under the Speech Learning Model (SLM) framework (Flege, 1995). Taken together, the results indicate that consonant learning needs to be evaluated in terms of position-by-position variants, rather than just being a general property of the overall consonant systems.
\end{abstract}

Keywords: Perceptual category mapping; Korean learners of English; Coda neutralization; Prosodic location; Speech Learning Model; Second Language Learning 


\section{Introduction}

A fundamental tenet of Flege's original Speech Learning Model (SLM: Flege, 1987, $1995,2002)$ is that the degree of success a language learner will have in approximating the production of a non-native (L2) speech segment depends on the perceptual similarity/dissimilarity of that segment to segments in the native language (L1). To operationalize this observation, earlier versions of the SLM typologically classified L2 sounds into "similar" and "new" classes, where "similar" sounds are persistently functionally approximated by a previously existing L1 sound, and "new" L2 sounds require the learning of a category distinct from the previously existing L1 categories. The SLM predicts that the "new" segments are not the categories that constitute continual problems in more accomplished learners, but it is the "similar" ones that remain problematic for the learners trying to develop native-like production and perception skills. This is because novel category formation is blocked for the "similar" sounds, while such blocking does not occur for the "new" sounds.

Various findings in L2 category research over the last twenty years have shown that this classification of L2 sounds with respect to their similarity to ones in the L1 is not dichotomous, but rather is gradient. For example, Guion, Flege, Akahane-Yamada, \& Pruitt (2000), studying the acquisition of English by Japanese speakers, noted that the difficulty of developing skills with regard to new segments varies widely; it is not the case that simply getting L1 categories out of the way will make the acquisition process easy for any segment. Both English /1/ and / $/$ / are "new" segments to Japanese learners of English since neither English category was identified as one of Japanese categories with a high goodness rating. However, more experienced Japanese learners showed some 
evidence of learning only for English /ג/ but not for English /1/. The authors suggested that such a difference must be related to the fact that English $/ \mathrm{d} /$ is less similar to a native category (i.e., Japanese /r/) than English /1/ is, indicating a gradiency to L2 category classification. (Also see Strange, Akahane-Yamada, Kubo, Trent, Nish, \& Jenkins, 1998, regarding Japanese listeners' perceptual assimilation of American English vowels for a similar conclusion.)

Park \& de Jong (2008) also indicate that the distinction between "new" and "similar" is more graded than a typological labeling would suggest. Park \& de Jong (2008) examined Korean EFL (English as a Foreign Language) learners' perceptual identifications of a set of anterior obstruents produced by American English talkers. Identification categories were of two types: Korean consonant categories in one task (Korean labeling task) and English consonant categories in the other task (Roman/IPA labeling task). The responses also included goodness-of-fit judgments for the Korean labeled responses. The results in the Korean labeling task showed that English voiceless stops $/ \mathrm{p} /$ and /t/ are perceptually very similar to Korean aspirated stops (i.e., they receive high goodness ratings) and non-sibilant fricatives /f/, /v/, / / /, and /ð/ clearly are "new" (i.e., they receive low goodness ratings), and have no similar reflex in the Korean system. English voiced stops $/ \mathrm{b} /$ and $/ \mathrm{d} /$ are, however, somewhere in between, exhibiting a systematically greater degree of similarity with Korean fortis and lenis stops than do the non-sibilant fricatives, but also being a systematically poorer fit than are the English voiceless stops to the aspirated Korean stops. Schmidt (1996) and Cho \& Lee (2007) also report similar results for English-to-Korean category mapping. 
The results from Park \& de Jong (2008), nevertheless, support the more basic contention of the SLM that segments in an L2 need to be evaluated in terms of their 'newness'. In their study, the Korean learners' perceptual identifications in the Korean labeling task were used to generate a mapping of the English to Korean categories, and to then estimate a matched Korean-to-English category mapping. The paths through the mappings were then modulated by the goodness-of-fit judgments to make quantitative predictions of the Korean listeners' accuracy and error patterns. These predictions were tested by examining the listeners' English identification responses to the same stimuli in the Roman/IPA labeling task. With appropriate use of the goodness-of-fit data to weight the probability of particular English responses associated with each Korean category, the model was very successful in quantitatively predicting the accuracy of the Korean responses to the English stops. Predicted accuracies deviated from actual accuracy by less than $6 \%$ for most stops with the exception of English /p/. Accuracies for the non-sibilant fricatives, however, were grossly under-predicted; the Korean learners were systematically much better with the fricative consonants than would be predicted on the basis of the English-to-Korean mappings. This pattern of results was interpreted as indicating that the learners' L1 categories could be said to explain the pattern of English identifications and their accuracy with the English stops, while their pattern of identification of the English fricatives suggested the development of new categories that were effectively separating the fricatives from the stops.

One other attribute of these new fricative categories was also noted; error rates involved with fricatives were higher than those between stops, suggesting that, while the new categories have the advantage of being built around the English productions, they are 
also less well developed, and so are more noisy. They are subject to more confusion with other categories than the similar stops are.

The current research seeks to replicate the findings of Park \& de Jong (2008) with another Korean EFL data set, and to apply the same methodology in answering two somewhat different questions. All of the segmental identifications in the previous work were for consonants in prevocalic word-initial (henceforth, onset) position. The first question, then, to be asked, is the degree to which mappings for one prosodic context (i.e., onset position) will generalize to other contexts, and if they do not, whether the mapping patterns found in these other prosodic contexts conform to the "newness" mapping predictions found in Park \& de Jong (2008). A second, more specific question is also pursued in the context of the particular L1 being tested, and concerns the effect of having systematic neutralization rules in the L1 on mapping between the L1 (Korean) and L2 (English), and on perceptual identification performance in the L2.

Concerning the first question, de Jong, Silbert, \& Park (2009) investigated the generalization of perceptual identification abilities across prosodic contexts among Korean learners of English and found that perceptual identification skills related to voicing in onset do not generalize to voicing perception in intervocalic and post-vocalic word-final (henceforth, $\operatorname{cod} a$ ) contexts. Listeners who were exceptionally accurate with voicing in onset were not necessarily exceptionally accurate with voicing in other contexts, and listeners who were less accurate in onset consonants were not necessarily less accurate in other prosodic contexts. This pattern of results was interpreted as indicating that the particular perceptual skills necessary for initial position are different from those for voicing in other prosodic contexts. The results from Cho \& Lee (2007)'s 
and Jang (2014)'s studies also suggest that perceptual identifications for one prosodic context are not likely to generalize into other contexts. Cho \& Lee (2007) examined the category mapping patterns between English and Korean consonants across prosodic contexts among Korean learners of English. They reported that the mapping patterns differed in different prosodic contexts; more diverse patterns were observed in prosodically weak position (e.g., coda) than in prosodically strong position (e.g., onset). Jang (2014) compared identification accuracies for English consonants in onset and coda positions among Korean learners of English, finding large differences in accuracy for the two positions; the accuracy was higher in the syllable initial than in the syllable-final position. These findings fit with previous work in the SLM line, which generally treats position-specific allophones as the targets of analysis (Flege, 1995). If this conclusion is appropriate to the current data, and thus mapping patterns differ by position, then these consonants in other contexts provide additional test cases for examining the general contention of Park \& de Jong (2008) that similarity classification ("newness") determines identification performance for the segments.

Concerning the second question, the current research specifically investigates the effect of Coda Neutralization in Korean on the mapping between the L1-Korean and L2English categories. Korean stops show a three-way contrast, between so-called fortis (or tense), lenis (or lax), and aspirated in all prosodic contexts except for coda position (Sohn, 1999). In coda position, the three-way laryngeal contrasts (between fortis, lenis, and aspirated) and the three-way manner differences (between stops, fricatives, and affricates) are neutralized into homorganic lenis stops, and some place contrasts (i.e., between palatals and coronals) are also neutralized (e.g., palatals are neutralized into the coronal 
lenis stop /t/) (Kim \& Jongman, 1996; Sohn, 1999). As a result, only three obstruents /p t $\mathrm{k} /$ appear (without any burst release, i.e., $\left.\left[\mathrm{p}^{\urcorner} \mathrm{t}^{\urcorner} \mathrm{k}\right\urcorner\right]$ ) in coda position, while 15 obstruents /p p' $\mathrm{p}^{\mathrm{h}} \mathrm{t} \mathrm{t}^{\prime} \mathrm{t}^{\mathrm{h}} \mathrm{s} \mathrm{s}^{\prime}$ t6 $\mathrm{t}^{\prime} \mathrm{tg}^{\mathrm{h}} \mathrm{k} \mathrm{k}^{\mathrm{\prime}} \mathrm{k}^{\mathrm{h}} \mathrm{h} /$ appear in onset position (Shin \& Cha, 2003). Kim \& Jongman (1996) reported that this Coda Neutralization was observed in production as well as in perception: durations of preceding vowels and closure durations of coda consonants $/ \mathrm{t} \mathrm{t}^{\mathrm{h}} \mathrm{s} /$ were not distinguishable from one another and native Korean listeners could not identify underlying coda consonants reliably. Most generative analyses capture this systematic distribution with neutralization rules that take lexical specifications of laryngeal and manner contrasts, and remove them in coda position (Sohn, 1999). Such analyses also capture the fact that various morphemes that do not exhibit laryngeal and manner contrasts in coda position do have such contrasts when produced with an attached enclitic or suffix beginning with a vowel. The question this situation raises with respect to approaches like the SLM is what the inventory of categories relevant for predicting L2 performance in neutralization cases should be.

One possible answer is that the inventory is simply determined on the basis of produced contrasts in a particular prosodic context. In this scenario, there are fewer obstruent categories in coda position in Korean, and thus there are likely to be fewer "similar" L2 English categories, since more of the English categories should be perceptually different from the very sparse collection of categories in the Korean coda cases. This is clearly the most likely prediction of the general mapping approach suggested by the SLM, since the SLM deals with target sounds as specific positiondependent allophones. 
Another possibility is, as one reviewer has pointed out, that released obstruents would be perceived in a different prosodic position such as in the following onset position due to perceptual epenthesis (Kabak \& Idsardi, 2007; de Jong \& Park, 2012). If this were the case, the number of "similar" L2 categories would not necessarily be fewer. Although this scenario is also plausible, we will focus our discussion on the first scenario. In the discussion, however, we further investigate this second possibility and explain why our data do not provide support for it.

A further question also arises, given the first scenario that the mapping is between position-specific allophones, as to which L2 segment is likely to be similar to the neutralized segments in the L1. In the Korean case examined here, the neutralization rules generally assume neutralization in the direction of an unreleased voiceless lenis stop (Sohn, 1999). Given the large number of differences between English 'voiced' and 'voiceless' stops, and unclear relationship between stop voicing and release patterns in coda position (Kang, 2003a), it is not clear how the mapping would work regarding the 'voiced' and 'voiceless' categories. In a simplistic approach, one might predict that unreleased voiceless stops are good candidates for "similar" L2 categories. Further, one might also predict that unreleased stops are likely to be "similar" L2 categories, regardless of its laryngeal specification, as suggested by Kabak \& Idsardi (2007, p. 44). Thus, both unreleased voiced and voiceless stops will be "similar" sounds. With this approach, the identity of manner of articulation (e.g., stops vs. fricatives) along with its detailed phonetic characteristics (i.e., a burst release) will play a role in determining the similarity. Alternatively, we may predict that neither English stops nor fricatives are 
"similar" L2 categories due to undetermined characteristics of the unreleased L1 segments in coda position.

In addition to the mapping issue, the second question concerns the effect of Coda Neutralization in Korean on perceptual identification performance regarding English consonants. On the one hand, in production, the SLM predicts that whichever L2 segments are not mapped onto the neutralized stops would not constitute continual problems among more experienced learners because they are "new" L2 sounds. That is to say, if the English productions sound very different from Korean productions, due to the unreleased nature of the Korean coda stops, then Koreans will build "new", unassimilated categories around the English coda stop productions. On the other hand, in perception, as per the results of Park \& de Jong (2008), "new" categories, while having the advantage of being built around the L2 categories, also exhibit more confusions. Hence, in perception, contrary to the SLM prediction on "new" L2 sounds in production, we would predict poor performance with coda consonants, if they all are to be classified as "new".

Toward similar conclusions, other analytic frameworks would also point out that the English productions may not just be different from the Korean categories, but might be more specific and hence more problematic for the Korean learners. For example, some analyses suggest that the Korean coda stops are underspecified for laryngeal features (or at least that the neutralized stops are somehow 'less marked' segments), constituting something of a default stop production, and the English categories are more specific. Markedness is often used to explain the order of acquisition in L2 phonology; 'less marked' L2 segments would be learned before 'more marked' ones (Eckman, 1977, 1991; Eckman \& Iverson, 1994; Major \& Faudree, 1996). Under this view, contrary to the 
SLM's prediction, we would predict, then, that L2 non-neutralized segments ('marked' segments) would be more difficult, and constitute something of a problem in the process of acquisition, despite being "new" segments.

To expand on this general viewpoint, the existence of a neutralization process itself may point to a general aspect of the L1 phonological system that will interfere with the acquisition process. One possibility is that a position-specific neutralization process might require less perceptual tuning to that particular prosodic position. Since the neutralization rule indicates a very small number of categories in the coda position, Korean learners may be 'detuned' to perceiving segmental information (especially the neutralized laryngeal and place of articulation contrasts) in such positions, and thus may find the acquisition of categories in such contexts as being exceptionally difficult. This notion of general perceptual sensitivity has been invoked in various L2 acquisition studies to explain persistent difficulties among L2 learners (e.g., Iverson, Kuhl, AkahaneYamada, Diesch, Tohkura, Kettermann, \& Siebert, 2003; McAllister, Flege, \& Piske, 2002). Perceptual training methods directing the learners' attention to specific phonetic dimensions are also based on the assumption that the learners' L1 experience influences their weighting of acoustic dimensions, resulting in greater sensitivity to some perceptual dimensions than to others (Guion \& Pederson, 2007; Pederson \& Guion-Anderson, 2010). Thus, a similar prediction can be made here with prosodic context; English uses postvocalic contrasts more extensively than does Korean, and thus we might predict that Koreans will have particular perceptual difficulty with post-vocalic contrasts that do not 
correspond to contrasts in the L1. ${ }^{1}$ (See Cebrian, 2000, regarding how L1 neutralization rules may influence L2 obstruent production.)

Models of perceptual assimilation also suggest that neutralization processes will interfere with learning. Presentation of these predictions, along with previous analyses of Korean learners of English (e.g., de Jong, Hao, \& Park, 2009), suggest that neutralization processes, since they in and of themselves are phenomena that map two or more categories onto one production, constitute a barrier to the discrimination of the categories. The Single Category (i.e., more than one nonnative categories assimilate to a single native phoneme) has been identified as a situations which yields low predicted discriminability in Best's Perceptual Assimilation Model (PAM: Best, McRoberts, \& Goodell, 2001; Best, McRoberts, \& Sithole, 1988; Also see Best \& Tyler, 2007, for PAM-L2). What this predicts for a mapping algorithm, such as that explored by Park \& de Jong (2008), is that most English categories will not have a high goodness-of-fit in coda position. Extending this prediction, in turn, to the Korean learners' L2 identification abilities, we would predict that "new" categories for most of the coda segments are not distinctively differentiated from other categories; thus, it would be exceptionally difficult to acquire these "new" sounds. This runs counter to the general predictions of the SLM with respect to "new" segments.

To summarize, we examine two questions in the current study. First, we investigate the degree to which mappings in onset position reported in Park \& de Jong (2008) will generalize to non-CV contexts. Second, we explore how Coda Neutralization in Korean

\footnotetext{
${ }^{1}$ Having fewer categories in one prosodic context is not necessarily disadvantageous at perceiving all segmental information in that position. For example, Chang \& Mishler (2012) report that Korean speakers are more accurate at perceiving the place of articulation of unreleased English stops in coda position than native speakers are. We are thankful to one reviewer for directing our attention to this point.
} 
will affect the category mapping between L1-Korean and L2-English and perceptual identification of English sounds. For the first question, we predict that the generalization across prosodic contexts will not occur, as in de Jong, Silbert, \& Park (2009), which reports no such generalization of perceptual identification skills. For the second question, the prediction is that the neutralization rules reduce the number of "similar" L2 categories and foster perceptual insensitivity to English segments in coda position, resulting in the development of "new" categories for most of the coda segments. We predict that these "new" segments in coda position will be difficult to learn, despite being "new" segments.

\subsection{Obstruents of Korean and English}

In this section, we briefly introduce some background on Korean and English obstruent systems. Korean stops show a three-way contrast, between so-called fortis, lenis, and aspirated, in all prosodic contexts except for coda position, whereas English stops exhibit a two-way contrast (Sohn, 1999). The places of articulation for both English and Korean stops are the same: bilabial, alveolar, and velar. Roughly speaking, English stops are acoustically similar to Korean stops in onset position, though the voicing contrast is somewhat different. For example, examining the corpus of 117 male and female Korean speakers across different ages, Kang (2014) reports mean Voice Onset Time (VOT) values of $17.18 \mathrm{~ms}, 45.95 \mathrm{~ms}$, and $63.76 \mathrm{~ms}$, for the fortis, lenis, and aspirated stops, respectively. ${ }^{2}$ (See Appendix B of Kim, 2012, for the summary of reported VOT values in studies from 1960 to 2011.) Lisker \& Abramson (1964) report

\footnotetext{
${ }^{2}$ Traditionally, VOT conveyed the three-way contrast in Korean stops. However, the VOT contrast between lenis and aspirated stops is undergoing a merger in Seoul Korean, and speakers are using the fundamental frequency (F0) of the following vowel more extensively to make the contrast. See Kang (2014) for more details.
} 
mean VOT values of $9 \mathrm{~ms}$ and $69.33 \mathrm{~ms}$, for English voiced ${ }^{3}$ and voiceless stops across three places of articulation, respectively. English has more fricatives than Korean; English has nine fricatives /f v $\theta \partial \mathrm{s} \mathrm{z} \int \mathrm{h} /$ and Korean has only three /s'/ (fortis 's'), /s/ (lenis 's'), and /h/. (See Cho, Jun, \& Ladefoged, 2002 and Kang \& Guion, 2006, for a review on acoustic properties of Korean stops and fricatives.) In the intervocalic and coda positions, Korean is noted to exhibit various allophonic differences from the onset position. For example, all Korean stops exhibit positive VOT values, except for lenis stops in intervocalic position. Lenis stops usually exhibit positive VOT values in onset position (Han \& Weitzman, 1970; Kagaya, 1974), while they tend to have negative VOT values (or voicing in closure) in word-medial, intervocalic positions (Jun, 1994; Kim, 1965; Silva, 1991 and 1992). For instance, when Silva (1992) measured the duration of voicing during the stop closure of lenis /p/, /t/, and / $/ \mathrm{k}$ in word-medial, intervocalic positions, overall $86 \%$ of the closure exhibited periodic vibration. English voiced stops show a similar intervocalic stop voicing. Keating (1984) reports that /b/ exhibits a substantial amount of closure voicing in word-medial, post-stressed intervocalic position, and at least some closure voicing in word-medial, pre-stressed intervocalic position. Also, English alveolar stops /t/ and /d/ are often realized as flaps intervocalically when the second vowel is unstressed (Ladefoged \& Johnson, 2015). Korean does not exhibit stressinduced allophony in its system. Unlike in English, categories in Korean are severely restricted in coda position. In English, segments that appear in onset position also freely appear in coda position (except for $/ \mathrm{h} /$ ). Further, released and unreleased stops occur in free variation (Ladefoged \& Johnson, 2015). In Korean, however, as previously

\footnotetext{
${ }^{3}$ They also report that one of their four speakers produced voiced stops with negative VOTs predominantly, and the mean VOT values for the voiced stops were $-97 \mathrm{~ms}$.
} 
mentioned, three-way laryngeal contrasts (fortis, lenis, and aspirated obstruents) and three-way manner differences (stops, fricatives, and affricates) are neutralized into homorganic unreleased lenis stops, and some place contrasts (i.e., palatals and coronals) into coronal unreleased lenis stops. As a result, only three obstruent categories $/ \mathrm{p} \mathrm{t} \mathrm{k/}$ appear, without any burst release, in coda position. It is notable that nine obstruents $/ \mathrm{t} \mathrm{t}^{\prime} \mathrm{t}^{\mathrm{h}}$ $s^{\prime}{ }^{\prime} t 6 t^{\prime}{ }^{\prime} 6^{\mathrm{h}} \mathrm{h} /$ are neutralized into /t/, and that /s/ rather than /t/ (which is the most frequently pronounced word final obstruent) is the most frequent word final obstruent of Korean nouns in orthography (Albright, 2008). Table 1 presents a sketch of the inventories of obstruent allophones in Korean and English; details concerning degree of voicing have been suppressed for simplicity's sake. (See Ladefoged \& Johnson, 2015 for more details on English consonant allophones.)

*** Insert Table 1 here $* * *$

\section{Methods}

This section consists of two parts overall. After describing the stimulus corpus and the participants, we will review the general procedure and the analysis methods, which are identical to the protocol in Park \& de Jong (2008).

\subsection{Talkers and Stimuli}

Two male and two female native speakers of American English produced the stimuli. All the speakers were in their late 20's and had a residential history dominated by the eastern Mid-west (Illinois, Indiana, Michigan, and Ohio). The speakers were asked to 
read a randomized list of nonsense words three times. For the perceptual experiments, we selected the clearer production from the first two repetitions unless both productions were mispronounced. When both productions were mispronounced, we used the third one. The nonsense words consisted of the vowel /a/ and a variety of consonants in four prosodic contexts with respect to the vowel: initial and prevocalic (onset), final and postvocalic (coda), and pre-stressed and post-stressed intervocalic positions. The original corpus included most of the non-dorsal consonants in English in the four prosodic contexts to cover the range of responses to a larger set of segmental neighbors. The current analyses, however, focus on the symmetrical set of eight obstruents /p b t d f v $\theta$ ð/ in VCV́ (prestressed intervocalic - aCá, e.g., /apá/), V́CV (post-stressed intervocalic - áCa, e.g., /ápa/), and $\mathrm{VC}($ coda $-\mathrm{aC}$, e.g., /ap/) positions, resulting in 96 test stimuli (=8 consonants $\times 4$ speakers $\times 3$ prosodic contexts). (See Park \& de Jong, 2008, for the results on the initial prevocalic segments.) The stimuli are presented in Table 2. The stimuli were recorded in a sound-attenuated recording room in the Linguistics Department at Indiana University, using an Electro Voice (model RE50) standing microphone and a TASCAM DA-30 MKII DAT recorder at a $44.1 \mathrm{kHz}$ sampling rate. The recordings were transferred from DAT to an Apple G4 in the Linguistic Speech Lab at Indiana University for editing.

\footnotetext{
*** Insert Table $2 * * *$
}

The productions exhibited a range of variation, both in terms of the allophonic makeup and vowel quality. All of the stimuli were subjected to narrow phonetic transcription 
with a visible spectrogram by the authors to obtain a general characterization. Prestressed intervocalic 'voiced' stops ranged from fully voiced to having partial devoicing with no aspiration. 'Voiceless' stops were devoiced with 30 to $110 \mathrm{~ms}$ of aspiration. Poststressed intervocalic stops exhibited a similar variation, though with slightly reduced aspiration ranging from 25 to $85 \mathrm{~ms}$, and with somewhat less devoicing. None of the intervocalic stops were flapped. In coda position, half of the labial stops ( 3 out of 4 coda $/ \mathrm{b} /$ and 1 out of 4 coda $/ \mathrm{p} /$ productions) did not exhibit an audible release, while the coronal stops were all released. One production of coda $/ \mathrm{b} /$ had a voiceless release, and one coda /t/ production was glottalized. All of the fricative productions exhibited audible noise. Vowels were longer before the 'voiced' obstruents (mean $=240 \mathrm{~ms}$ ) than before the 'voiceless' ones (mean $=201 \mathrm{~ms}$ ) in coda position. As to vowel quality, both male speakers exhibited F1 measurements between 650 and $800 \mathrm{~Hz}$ and F2 measurements from 1200 to $1300 \mathrm{~Hz}$ when we examined both stressed and unstressed vowels in the corpus; thus, all vowels would be classified as low, back vowels, though one speaker tended to have slightly lower vowels than the other. The female speakers differed more. Regarding the stressed vowels, one speaker produced very open and more front-sounding vowels, exhibiting F1 values of $1100 \mathrm{~Hz}$ with F2 values of approximately $1500 \mathrm{~Hz}$. The other speaker, by contrast, produced less open vowels, with F1 values ranging from 750 to $850 \mathrm{~Hz}$, and similar F2 values of approximately $1450 \mathrm{~Hz}$. The stressed vowels throughout the corpus would all fall within a range classified as low, back vowels. Vowels in unstressed locations, while exhibiting shorter durations, were not reduced to schwa, with F1 values for the male speakers ranging from 650 all the way to $750 \mathrm{~Hz}$. The 
one female speaker had F1 values ranging from 900 to $1000 \mathrm{~Hz}$ for unstressed vowels, and the other with more central values of around $700 \mathrm{~Hz}$.

\subsection{Listeners}

Forty listeners (28 female and 12 male; mean age $=24.97$ years; 30 from Seoul/Gyeonggi area and 10 from other areas) were recruited from the undergraduate students at Kyonggi University, in Suwon (near Seoul), Korea, and all were paid for participating in the experiment. These listeners also participated in the study reported in Park \& de Jong (2008). All the listeners had been studying English for more than 7 years as a regular course in school. However, their training was mainly in written English and their exposure to English spoken by a native speaker was limited; none had lived in an English speaking country prior to the experiment. ${ }^{4}$ Previous analyses indicate that there is a broad range of perceptual abilities of English segments among the listeners. For example, de Jong, Silbert, \& Park (2009) examine the same listeners in the current study

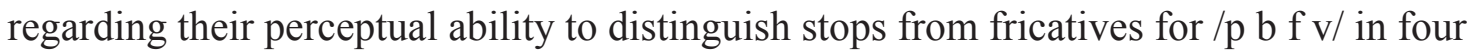
prosodic contexts $(\mathrm{CV}, \mathrm{VCV}, \mathrm{V} C \mathrm{~V}, \& \mathrm{VC})$ and report the accuracy rate ranged from $39 \%$ to $92 \%$. Thus, it is difficult to assume a homogeneous English listening proficiency among the learners.

\subsection{Procedure}

\footnotetext{
${ }^{4}$ One reviewer was concerned whether the level of English of our subjects qualifies as the amount of experience required for accurate category formation of "new" sounds under the SLM. Since the same listeners showed evidence for different patterns for "new" and "similar" English sounds in prevocalic onset position (Park \& de Jong, 2008), we expect to be able to detect these differences in these same subjects in other prosodic positions. Nevertheless, it might be more appropriate to examine learners having massive exposure to spoken English for the study of L2 category development.
} 
All of the stimuli were randomized and presented only once to groups of approximately 10 listeners concurrently. The experiment was conducted in a quiet room at Kyonggi University in Korea. The stimuli were played from a CD through two ceilingmounted loud speakers (Model: Atlantis AS-B6) connected with a PC, with the interstimulus interval of 5 seconds. Note that the data was collected from the open-field experimentation rather than in more controlled way (e.g., individual experimentation with stimuli presentation through headphones in a sound treated room). In addition to the advantage of collecting the data in a short time, this open-field experimentation reflects a more realistic L2 learning and performance situation. No feedback was given during any of the sessions. The listeners knew that the stimuli had been produced by native speakers of English, and they were also told that the stimuli were not real English words. Five practice items were played before each task to avoid any misunderstanding of the experimental procedure. There was a native Korean proctor conducting the experiment, mitigating any misunderstanding about the mechanics of the tasks resulting from lack of English proficiency on the part of the listeners.

There were two perception experiments: a mapping experiment and an identification experiment. Each perception experiment included two different tasks: 1) labeling each stimulus, and 2) giving a gradient evaluation of their response. Each experiment was performed with a different set of labels: the mapping experiment with Korean consonantal characters ${ }^{5}$ and the identification experiment with Roman and IPA symbols. Note that these two experiments are the same task with different probes. Twenty listeners were asked to label the stimuli with Korean orthography first (the mapping experiment),

\footnotetext{
${ }^{5}$ This mapping experiment with L1 orthographic labels is also known as a perceptual assimilation task (e.g., Lengeris, 2009) or an orthographic classification technique (e.g., Flege, 1991).
} 
and then to label the same stimuli with the Roman and IPA symbols (the identification experiment) on a later day. The other twenty listeners did the identification experiment on an earlier day.

In the mapping experiment, the listeners chose the consonant they heard from 13 alternatives presented in Korean orthography. The 13 alternatives were determined through pilot work to cover all of the likely responses for the core obstruents in the corpus. In addition, to ensure that we had covered all of the alternatives, along with the 13 alternatives, they were also provided a blank for writing down what they heard, if there was no match between a stimulus and the pre-selected alternatives. The Korean orthography is a phonemic system and there was no apparent difficulty in using the Korean alphabet for the choices. Following each mapping response, the listeners were also asked to mark how good they considered the label to be on a scale from 1 to 7 . If they thought that their choice was not similar to the stimulus at all, they would mark "1". On the other hand, they were to mark "7" if they felt that the label was an exact match with the stimulus.

In the identification experiment, the listeners were asked to choose the consonant of the stimuli from 15 alternatives in the Roman/IPA labeling. They could also write down what they heard, if there was no correspondence between a stimulus and the choices. Since IPA symbols $/ \theta /$ and $/ \delta /$ were also included in the choices, we provided example words indicating which sound each symbol corresponds to before the task. The example words were selected from among familiar English words to the listeners, exhibiting the stimulus consonants in different prosodic contexts. Key words for each target sound were 
also presented at the top of each answer sheet. ${ }^{6}$ It should be noted that, since the listeners all had extensive experience with written English, they were very familiar with the Roman orthographic probes. Also, since English language education in Korea typically involves instruction in the contrast between the voiced and voiceless dental fricative (typically using IPA symbols to indicate the difference), the students did not seem to have any problems interpreting the IPA response alternatives. Following each identification response, the listeners were asked to indicate how confident they were in the response on a 7-point Likert scale. Appendix A shows the instructions and the answer sheets for the tasks.

\subsection{Analysis}

Park \& de Jong (2008) present the development of a quantitative technique to assess the degree to which L2 identification patterns indicate a reliance on L1 categories, which is interpreted as evidence for the entanglement of the L1 and L2 categories. A given identification could be due to reliance on an L1 category and the additional mapping of that L1 category onto the L2 response category, or it could be due to the development of a (new) L2 category. The mapping data (from the mapping experiment) are used to distinguish these two possibilities. Our analyses develop predictions based on the mapping data as to what a null hypothesis of listeners' using L1 categories for L2 identification would predict for each segment in terms of identification accuracy. The identification data (from the identification experiment) are used to evaluate the predictions. If identification accuracies are greater than what is expected based on the

\footnotetext{
${ }^{6}$ The prosodic context of the consonant in the key words did not match that of each stimulus consonant because we presented stimuli with all four prosodic contexts (i.e., CV, VCV́, V́CV, \& VC) in the same block to the listeners. The keywords were fixed at the top of each response sheet.
} 
mapping data, it would then be attributable to development beyond the L1 categories. Additionally, if identification accuracies are poorer than what is predicted from the mapping data, it would then be attributable to additional decrements in performance not indexed in a segmental mapping task. One such decrement might be the presence of general neutralization rules.

Two approaches for generating predictions concerning L2 identification accuracy from the mapping data are included. The first approach (Unweighted model) models the probability of an L2 production to an L2 response as the sum of the probabilities of getting the L2 response by means of each L2-to-L1 mapping. Each probability is the product of the L2-to-L1 mapping probability (the probability of an L2 production mapping onto an L1 category) and the L1-to-L2 mapping probability (the probability of that $\mathrm{L} 1$ category indicating an instance of the L2 response category). These probabilities need to be summed across a number of potential paths that will go from an L2 production through different L1 categories onto an L2 category, since multiple pathways are often possible. For example, the data in Park \& de Jong (2008) indicate English onset /d/ maps onto Korean lenis $/ t /$ and fortis $/ t ' /$, and hence both of these represent categories which Korean listeners will reasonably map on their English /d/ category in an English (Roman/IPA) identification experiment, under the null hypothesis that they are relying on their L1 categories to do L2 identification. In the Korean mapping experiment, $84 \%$ of the English onset /d/s were mapped onto the Korean category lenis /t/. This is the L2-toL1 mapping probability. To get the L1-to-L2 mapping probability, we invert the map, and estimate the probability that the Korean lenis /t/ category corresponds to an English /d/ across the set of data. Considering all cases in which the Korean lenis / $t /$ was employed, 
of these only $45 \%$ were cases of English /d/, since the lenis /t/ label was also applied to other English categories, including /v/ (18\%), / // (78\%), and / $\theta /(7 \%)$. This is the L1-toL2 mapping probability. The predicted accuracy for English /d/ on the basis of using the Korean lenis $/ t /$ category, then, is $38 \%(=0.84 \times 0.45)$. This is not the total predicted accuracy, however. English /d/ were also labeled as Korean fortis /t'/ 14\% of the time, and the $/ \mathrm{t} /$ category in turn is also used in the context of English $/ \mathrm{d} / 37 \%$ of the time. Thus, the predicted accuracy for English /d/ through the Korean / $\mathrm{t} /$ category is 5\% (= $0.37 \times 0.14)$. When we sum up the overall accuracy given both of these potential paths to an accurate response, the total predicted accuracy for English $/ \mathrm{d} /$ is $43 \%(=0.38+0.05)$.

The second approach (Weighted model) is identical to the first, except that it takes the second term, the L1-to-L2 mapping probability, and weights it by the mean goodness rating for that particular L1-L2 category mapping. One weakness of the first approach is that goodness of fit is determined entirely in terms of usage of a label, without regard to whether the use of the label is likely to be indicative of such usage in general. The prediction based on such proportionate measures alone, then, is at best an indirect indicator of the goodness of fit of the stimulus to the L1 category. Mean goodness ratings augment the estimation of the match between the L1 and L2 categories (Cebrian, 2006). Using a method similar to Guion et al.'s (2000) fit index, each categorical mapping is weighted by the mean goodness rating of all the cases in which that L1 category is applied to a stimulus of a specific L2 category. We decided to use the mean values of goodness rating, rather than the median values (e.g., as in Strange et al., 1998), in order to pursue finer predictions with weighting. In order to increase the dynamic range of the goodness ratings, the lower end of the response scale was removed by subtracting a lower 
threshold determined as the lowest mean value for any of the L1 category mappings which were used more than $7.69 \%$ (i.e., chance level). The choice of threshold value is a free parameter that allowed very close prediction of L2 stop accuracy by the Korean listeners. We provide the formulas for each model with examples of calculating the predicted accuracy in Appendix B. Since there are a number of decisions which go into determining these weightings, Park \& de Jong (2008) present both weighted and unweighted results in order to allow us to know the effect of this weighting on the model. Since different weightings can produce different degrees of fit for different segments, it is important to know the effect of weighting to evaluate what the model is telling us concerning the effect of "newness" in the overall fits of the model to the data. (See Park \& de Jong, 2008, for more detailed discussion of these two approaches.)

While our predictions for the intervocalic contexts duplicate previous findings from Park \& de Jong (2008), the predictions for coda position are quite different. Specifically, for intervocalic contexts, if the category mapping is consistent across prosodic context, we would expect predictions from the mapping data to be quite accurate for stops, but to be lower than what is actually observed for fricatives, which are "new". For coda position, there are various hypothetical patterns. If neutralization simply removes L1 categories and the neutralized stop category is similar to English voiceless stops, then predicted values should be similar to those for the voiceless stops, and lower than what is obtained for voiced stops and fricatives, since all of these categories are "new". If the burst release of English coda stop plays a role in the category mapping, then either unreleased voiceless stops or both unreleased voiced and voiceless stops are similar to the neutralized L1 categories. Thus, the predicted values should be accurate as to what is 
actually observed only for voiceless stops or both for unreleased voiced and voiceless stops. If neutralization interferes with perceptual mapping for all of the categories, then predicted accuracy should be consistently higher than what is actually observed for all of the segments. That is, neutralization may systematically introduce a reduction of ability to perceive contrasts in the coda position.

In addition to comparing the predictions from the L1-based models with the actual identification accuracy, we also examine the results from the mapping experiment regarding the number of L1 categories mapped on each L2 segment and the mean goodness of fit ratings for each L2 sound. Park \& de Jong (2008) indicate that "new" L2 sounds are often characterized by one-to-multiple (L2-to-L1) category mapping and relatively low goodness ratings. On the one hand, we predict that one-to-multiple mapping with relatively low goodness ratings will be observed for most L2 sounds in coda context, while mapping patterns and goodness ratings will distinguish some sounds (i.e., more "similar" sounds) from the other (i.e., more "new" sounds) in intervocalic contexts.

\section{Results}

In Sections 3.1 and 3.2, we present the results from the mapping (Korean labeling) and the identification (Roman/IPA labeling) experiments, respectively. The analyses are based on 160 tokens for each stimulus ( $=4$ talkers $\times 40$ listeners), totaling 3,840 tokens

for each experiment $(=4$ talkers $\times 40$ listeners $\times 3$ prosodic contexts $\times 8$ segments $)$. The results from the mapping experiment are used to generate predictions of L2 identification accuracy. These predictions are tested by how the Korean listeners actually identified 
English stimuli in the identification task. Section 3.3 presents the predictions from two approaches, one with and the other without considering mean goodness rating data, for each prosodic context. We also discuss to what extent the Korean listeners' actual identification accuracy could be predicted in terms of L1 category dependency.

\subsection{Identification patterns with Korean orthography}

Tables 3 to 5 present the proportion of Korean labeling chosen for each stimulus with its mean goodness ratings in VCV́ (pre-stress intervocalic), V́CV (post-stress intervocalic), and $\mathrm{VC}(\operatorname{cod} a)$ contexts, respectively. At least three pieces of information can be found in the tables: how many and which Korean categories are connected to a particular English category, and how strong the connection is between the Korean and English categories. The proportion of the labeling choices, along with the mean goodness rating, will show the strength of connections. The higher the proportion and the mean goodness rating are, the stronger the connection is.

In VCV́ position (Table 3), we observe that some English categories are connected to a single Korean category while others to more than one Korean category. All English stops $(/ \mathrm{p} /, / \mathrm{t} /, / \mathrm{b} /$, and $/ \mathrm{d} /)$ and $/ \mathrm{v} /$ show one-to-one category matching pattern between English and Korean categories. ${ }^{7}$ However, among these categories, we see different degrees of strength between English and Korean category connections. When we examine the mean goodness ratings of modal responses, the ratings were higher for English voiceless stops /p/ (6.00) and /t/ (6.24) than for English voiced stops /b/ (5.72)

\footnotetext{
${ }^{7}$ Since our participants chose the answer from 13 alternatives, a chance level to choose any label is $7.69 \%$ $(100 \div 13=7.69)$. Thus, we did not consider Korean labeling choices with proportion less than $7.69 \%$ (e.g., Korean /t/ choices for English /v/: 6.9\%; Korean /p'/ choices for English / $/:$ : 6.9\%) in our description of the mapping patterns. In Tables 3 to 6 , proportions are shown in grey if they do not exceed the chance level.
} 
and /d/ (5.56), and also than for /v/ (5.06). Further, although Korean lenis /p/ was mostly used to label English / $\mathrm{v} /$, the proportion of this labeling (74\%) is somewhat lower compared to the proportions of modal responses for stops, which are 89\% (for English /p/) or higher. Another observation in these one-to-one mapping patterns is a systematic mapping between the English and Korean laryngeal contrasts. On the one hand, all English voiceless stops were labeled as Korean aspirated stops: English voiceless stops $/ \mathrm{p} /$ and $/ \mathrm{t} /$ were labeled as Korean aspirated stops $/ \mathrm{p}^{\mathrm{h}} /$ and $/ \mathrm{t}^{\mathrm{h}} /$, respectively. On the other hand, English voiced stops and /v/ were labeled as Korean lenis stops: English /b/, /d/, and $/ \mathrm{v} /$ were labeled as Korean $/ \mathrm{p} /, / \mathrm{t} /$, and $/ \mathrm{p} /$, respectively.

English fricatives, except for $/ \mathrm{v} /$, show connections with two or more Korean categories. English voiceless fricatives show a one-to-two category mapping pattern between English and Korean categories. Both Korean fortis and aspirated categories were used to label English voiceless categories. For example, English /f/ was labeled with both Korean $/ \mathrm{p}^{\mathrm{h}} /$ and $/ \mathrm{p} \%$. English $/ \theta /$ was labeled with both Korean $/ \mathrm{s}^{\prime} /$ and $/ \mathrm{t} \%$. The mean goodness ratings for English voiceless fricatives were lower than those for English categories exhibiting a one-to-one mapping pattern. The highest rating for modal responses among English voiceless fricatives (i.e., 4.56 for $/ \theta /$ ) was lower than the rating for $/ \mathrm{v} /$ (5.06), which was the lowest mean goodness rating for modal responses among English categories with a one-to-one mapping pattern. English /ð/ was labeled with three Korean categories: Korean /t/, /p/, and /L/. These labeling results may simply reflect Korean listeners' difficulty in choosing Korean categories for English fricatives which are not present in Korean sound system. In general, English stops were persistently rated as more similar to some Korean counterpart than fricatives. A Wilcoxon matched-pairs 
signed-rank test confirms this observation; the goodness ratings were significantly higher for English stops $($ Median $=6.00)$ than for fricatives $($ Median $=4.67), z=-5.46, p<.01$ (two-tailed), $r=-0.61$.

*****Insert Table 3 here

In V́CV position (Table 4), we also observe one-to-one and one-to-multiple category mapping patterns between English and Korean categories. However, the mapping patterns between categories are different in this position from those in the VCV́ position. The connections between English and Korean categories are noisier in general. English stops /b/ and /t/ still show one-to-one mapping patterns as in the VCV́ position, though the proportions for modal responses were smaller and the mean goodness ratings were lower in the V́CV position. For instance, English $/ \mathrm{t} /$ was perceived as Korean $/ \mathrm{t}^{\mathrm{h}} /$ in $96 \%$ of the cases and the mean goodness rating was 6.24 out of 7.00 in the VCV position. The same English category was perceived as Korean $/ \mathrm{t}^{\mathrm{h}} /$ in $84 \%$ of the time with the mean goodness rating 5.87 in the V́CV position. Rather than displaying a one-to-one mapping pattern, English /p/ shows a one-to-three category mapping pattern: the Korean listeners used all three Korean labial stops $/ \mathrm{p}^{\mathrm{h}} /, / \mathrm{p} /$, and /p'/ to label English $/ \mathrm{p} /$. The listeners also used two Korean categories, Korean /t/ and /p/, for English /d/. Similarly, English fricatives also show noisier connection patterns. For example, English /f/ was labeled with four Korean categories: Korean $/ \mathrm{p}^{\mathrm{h}} /, / \mathrm{p} /, / \mathrm{p} \%$, and $/ \mathrm{s} /$. English $/ \theta /$ was also labeled with four Korean categories: Korean $/ \mathrm{p}^{\mathrm{h}} /, / \mathrm{s} \%, / \mathrm{t} \%$, and $/ \mathrm{p} \%$. These two English fricatives were labeled with only two Korean categories in the VCV́ position. 
Another observation is that the mean goodness ratings for English stops are lower in this position, compared to that in the VCV position. When we examine the mean goodness ratings of modal responses for English stops in VCV́ position, the ratings for English voiceless stops were 6.00 and those for English voiced stops were 5.56. However, none of the mean goodness ratings for any English stops in the V́CV position is higher than 5.87. A Wilcoxon matched-pairs signed-rank test confirms this observation; the goodness ratings for English stops were significantly higher in VCV́ (Median =6) than V́CV $($ Median $=5), z=8.34, p<.01, r=0.23$. We do not observe such a mean goodness rating difference for English fricatives in the two intervocalic positions.

***** Insert Table 4 here.

In the $\mathrm{VC}$ position (Table 5), we do not observe any one-to-one category mapping patterns but only one-to-multiple category mapping patterns. For example, Korean listeners chose Korean $/ \mathrm{t}^{\mathrm{h}} /(73 \%)$ and $/ \mathrm{s} /(11 \%)$ for English $/ \mathrm{t} /$, which was perceived as a single category Korean $/ \mathrm{t}^{\mathrm{h}} /$ in at least $84 \%$ of the time in other prosodic locations. The $/ \mathrm{s} /$ response for English coronal stops /t/ and /d/ is also unique to the VC position. Korean /s/ was chosen $11 \%$ and $16 \%$ of the time for English $/ \mathrm{t} /$ and $/ \mathrm{d} /$, respectively. In this position, the mean goodness ratings do not show the difference between stops and fricatives, except for English /t/. Mean goodness ratings for stops, except English /t/, were a little above 4.00 for modal responses (ranges between 4.06 and 4.33), as were those for fricatives (ranges between 4.06 and 4.20). A Wilcoxon matched-pairs signed-rank test indicates that the goodness ratings were not significantly different from each other for 
English stops $($ Median $=4)$ and fricatives (Median $=4), z=-1.31, p=.19$ (two-tailed), $r$ $=-0.03$. We also notice that Korean listeners chose "Others" and Korean $/ \mathrm{h} /$ as a label for English consonants. The Korean $/ \mathrm{h} /$ label was used more than $7.69 \%$ (chance level) for all English consonants, except for /p/,/t/, and /d/. The "Others" response was used more than $7.69 \%$ for the half of the eight English consonants. Lastly, Korean fortis stop responses, such as $/ \mathrm{p}^{\prime} /$ and $/ \mathrm{t} /$, were rare, whereas Korean bilabial stop responses were often chosen, even for English coronal sounds such as /// and /d/.

******Insert Table 5 here

In Section 2.4, we outlined the possibility that the release of English coda stop might play a role in the category mapping. All coronal stop stimuli were released in $\mathrm{VC}$ position, but 4 out of 8 labial stop stimuli were not released; 1 out of 4 /ap/ and 3 out of 4 /ab/ stimuli were unreleased coda stops. Thus, we present the results separately for the unreleased and released labial stop stimuli in Table 6. Note that the number of tokens for each English category was different. The analysis was based on 40 tokens ( $=1$ talker $\times$ 40 listeners) for unreleased $/ \mathrm{p} /$ and released $/ \mathrm{b} /$, whereas there were 120 tokens $(=3$ talkers $\times 40$ listeners) for released $/ \mathrm{p} /$ and unreleased $/ \mathrm{b} /$ for the analyses.

******Insert Table 6 here

Compared to the general mapping patterns presented in Table 5, we do not observe particularly different patterns here. We still see one-to-multiple category mapping 
patterns, many $/ \mathrm{h} /$ and "Others" responses, relatively low mean goodness ratings both in released and unreleased labial stops. When we compare the results in terms of the release pattern, the overall mean goodness ratings did not differ from each other: 3.84 and 3.83 for the released and unreleased labial stops, respectively.

\subsection{Identification patterns with the Roman/IPA symbols}

In this section, we present results from the identification experiment with the Roman/IPA labeling. Tables 7 to 9 show the proportions of English categories chosen for each stimulus, along with the 40 listeners' mean goodness ratings in VCV́, V́CV, and VC positions, respectively. As in Section 3.1, we present the results for the released and unreleased labials in VC position separately in Table 10. Modal responses are marked in bold and proportions are shown in grey if they do not exceed the change level 6.66\% $(100 \div 15=6.66)$. The Korean listeners' modal responses agree with correct identification of English sounds, except for / $/$ in V́CV position, and /ð/ in VC position;

the Korean listeners' most frequent response for /v/ stimuli in V́CV position was /b/ $(50 \%)$ rather than $/ \mathrm{v} /(33 \%)$, and that for / $/$ / stimuli in $\mathrm{VC}$ position was $/ \mathrm{v} /(20 \%)$ rather than / $/$ $(2 \%)$.

*** Insert Tables 7, 8, 9, and 10 here

Considering also the error patterns, the Korean listeners identified English sounds differently when they appeared in different prosodic contexts. For example, English /p/ was identified as either/p/ or /f/ in VCV́ position (Table 7); however, the same sound 
was additionally identified as /b/ in V́CV position (Table 8). Further, the Korean listeners chose "Others" at a rate of $19 \%$ for this sound, along with $/ \mathrm{p} /, / \mathrm{b} /, / \mathrm{f} /, / \mathrm{t} /$, and $/ \mathrm{h} /$ in $\mathrm{VC}$ position (Table 9), suggesting the listeners' difficulty of identifying English $/ \mathrm{p} /$ in this particular prosodic location. Such English identification pattern changes in different prosodic contexts were observed for all investigated sounds. Overall identification accuracies for English sounds and mean confidence ratings also demonstrate prosodic influence. Overall, the Korean listeners identified sounds the best in VCV́ context (69.63\%), then in V́CV context (47.88\%), and the worst in VC context (36\%). A Friedman two-way ANOVA indicates that the identification accuracies of the listeners were significantly different from one another in different prosodic contexts, $\chi^{2}(2)=$ 73.72, $p<.01$ (two-tailed). According to the Wilcoxon matched-pairs signed-rank tests, the identification accuracy was significantly higher in VCV́ than in V́CV, $z=5.52, p$ $<.01$ (two-tailed), $r=0.61$, and VC contexts, $z=5.52, p<.01$ (two-tailed), $r=0.61$, and that was higher in V́CV than in VC context, $z=4.73, p<.01$ (two-tailed), $r=0.52$. Regarding the mean confidence ratings, the Korean listeners were more confident in their choices of voiceless stops than other sounds in VCV́. The mean confidence ratings of the modal responses for $/ \mathrm{p} /$ and $/ \mathrm{t} /$ were 6.07 and 6.21 , respectively, while those for other sounds were lower than 6 (e.g., 5.78 for /f/ and 5.74 for /b/). However, the mean confidence ratings for the voiceless stops were lower in different prosodic contexts. Such changes were more noticeable for /p/: 5.19 in V́CV and 3.71 in VC. The mean confidence ratings for the voiced stops were also lower in $\mathrm{VC}$ compared to other prosodic contexts (e.g., 5.74 in VCV́, 5.31 in V́CV vs. 4.25 in VC for /b/), while those for the voiceless 
fricatives /f/ and / $/$ / were similar across prosodic contexts (e.g., 5.78 in VCV́ vs. 5.67 in V́CV vs. 5.51 in $\mathrm{VC}$ for /f/).

Finally, the releases of the coda stops do not seem to appreciably influence the identification accuracy or mean confidence rating; the accuracy and the ratings were low for both released and unreleased labial stops. Although the released labial stops exhibited a higher accuracy than their unreleased counterparts, the accuracy differences were only $5 \%$ and $7 \%$ for the $/ \mathrm{p} /$ and $/ \mathrm{b} /$ pairs, respectively. Also, the overall mean confidence ratings were higher for unreleased /p/ (3.78) than for its counterpart (3.55), while the opposite was true for unreleased /b/ (3.53) and for released /b/ (4.03).

In general, the Korean listeners identified voiceless sounds better than voiced ones, though such a pattern also seems to be affected by prosodic context and there are some exceptions. On the one hand, overall accuracy was higher for voiceless sounds than for voiced ones in VCV́ and VC positions, and Wilcoxon matched-pairs signed-rank tests confirm these observations: $78.25 \%$ (voiceless) vs. $61 \%$ (voiced) in VCV́, $z=4.61, p$ $<.01$ (two-tailed), $r=0.51$, and $48.75 \%$ (voiceless) vs. $23.25 \%$ (voiced) in $\mathrm{VC}, z=5.32$, $p<.01$ (two-tailed), $r=0.59$. However, in $\mathrm{VC}$ position, the accuracy was higher for $/ \mathrm{b} /$ (28\%) than for its voiceless counterpart /p/ (22\%). On the other hand, in V́CV position, overall accuracy was similar for voiced and voiceless sounds: $47 \%$ (voiceless) vs. $48.75 \%$ (voiced), $z=-.78, p=.43$ (two-tailed), $r=-0.08$. However, the accuracies were higher for $/ f /(42 \%)$ and $/ \mathrm{t} /(81 \%)$ than for their voiced counterparts /v/ (33\%) and /d/ (53\%), respectively. Another observation is that the Korean listeners were better at identifying stops than fricatives only in intervocalic contexts. Overall accuracy was higher for stops than for fricatives in the intervocalic contexts, as confirmed by the Wilcoxon matched- 
pairs signed-rank tests: $79 \%$ (stops) vs. $60.25 \%$ (fricatives) in VCV́, $z=4.49, p<.01$ (two-tailed), $r=0.50$, and $59.50 \%$ (stops) vs. $36.25 \%$ (fricatives) in V́CV, $z=4.75, p$ $<.01$ (two-tailed), $r=0.53$. However, the overall accuracies were similar for stops and for fricatives in VC: $39.25 \%$ (stops) vs. $32.75 \%$ (fricatives), $z=1.62, p=.10$ (two-tailed), $r=0.18$. Again, the influence of the prosodic contexts appears here as well.

\subsection{Predicting identification patterns from category mapping}

In this section, we present the extent to which L1 labeling patterns with goodness rating data can account for L2 identification patterns. As in Park \& de Jong (2008), we generated a bidirectional perceptual mapping between English and Korean categories and constructed two versions of L1 category dependence models, the unweighted model and the weighted model, to predict how Korean listeners would identify English sounds. These predictions are based on the mapping data in Section 3.1. Then, we compared the models' predictions with the Korean listeners' actual identification performance with the L2 (or Roman/IPA) labeling, which was presented in Section 3.2. The only difference between two models is consideration of goodness rating data in their predictions; the weighted model incorporated goodness rating data while the unweighted model did not. (See Section 2.4 and Appendix B)

\subsubsection{VCV́ position}

Figure 1 illustrates the bidirectional perceptual mapping between English and Korean categories in VCV́ context. In this figure (and also in other bidirectional perceptual mapping figures), the thickness of the connecting lines corresponds to the proportions of 
times two categories are connected. Connections less than $7.69 \%$ of the time are not shown. The mappings of English to Korean categories (left panel) are simply a visual summary of the proportion of L1-Korean label usage for L2-English categories, which was presented in Table 3. The mappings of L1-Korean to L2-English categories (right panel) were constructed based on the probability of an L1-Korean category indicating an instance of an L2-English category. Note that the English-to-Korean (left panel) and the Korean-to-English (right panel) perceptual category mappings are not just symmetrical versions of one another. For example, the line connecting English $/ \mathrm{p} /$ and Korean $/ \mathrm{p} /$ (left panel) is thicker than that connecting Korean $/ \mathrm{p}^{\mathrm{h}} /$ and English $/ \mathrm{p} /$ (right panel). This is because the Korean listeners used Korean $/ \mathrm{p}^{\mathrm{h}} /$ for more than one English category; the Korean listeners labeled English /p/ and /f/ with Korean $/ \mathrm{p}^{\mathrm{h}} /$ at a rate of $89 \%$ and $66 \%$, respectively. If we add up these two categories labeled with Korean $/ \mathrm{p}^{\mathrm{h}} /$, only $57 \%$ (= $0.89 \div(0.89+0.66))$ were the cases of English $/ \mathrm{p} /$ in Korean $/ \mathrm{p}^{\mathrm{h}} /$ category. Therefore, the highly probable mapping from English $/ \mathrm{p} /$ to Korean $/ \mathrm{p}^{\mathrm{h}} /(89 \%)$ becomes less probable from Korean /p $/$ to English /p/ (57\%).

To predict how the Korean listeners would identify English sounds if they use only L1-Korean categories in their L2 identification, we sum up the products of the proportions for each connection to each Korean label (i.e., lines in the left panel) to a particular English response label connected to that Korean label. The unweighted model followed this method without considering the goodness rating data; however, the weighted model incorporated the goodness rating data in the prediction by weighting the predicted accuracy with the mean goodness ratings for the L1-L2 category mapping directly involved. As in Park \& de Jong (2008), we removed the lower end of the 
response scale to increase the dynamic range of the goodness ratings. In the case of predictions in VCV́ position, we subtracted 3.5 from the mean goodness ratings. This lower threshold 3.5 was determined because the lowest mean value for any Korean label usage of $7.69 \%$ or more responses was larger than $3.5 .{ }^{8}$ If we go back to the example of English $/ \mathrm{p} /$ and Korean $/ \mathrm{p}^{\mathrm{h}} /$ in the previous paragraph, with such weighting, the probability that Korean $/ \mathrm{p}^{\mathrm{h}} /$ indicates an instance of English $/ \mathrm{p} /$ (i.e., the L1-to-L2 mapping $)$ is about $77 \%(=(0.89 \times 2.5) \div\{(0.89 \times 2.5)+(0.66 \times 1.02)\})$ rather than $57 \%$. Thus, the predicted accuracy for correct identification of English /p/ would be about $69 \%$ $(=0.89 \times 0.77)$.

Figures $2 \mathrm{a}$ and $2 \mathrm{~b}$ plot the identification accuracy in the identification experiment (with the Roman/IPA labeling) for each of the eight target segments against predictions of the unweighted and the weighted models, respectively. The $x=y$ diagonal indicates perfectly accurate predictions. Hollow circles represent stops and filled ones indicate fricatives. There is a general correlation between predicted and actual accuracies in both models ( $R^{2}=0.62$ and 0.61 for the unweighted and the weighted models, respectively), suggesting that the Korean listeners' L2 identification is largely dependent on L1-L2 category mappings. However, the two models differ in showing the distinction between stop and fricative categories. The unweighted model does not show distinctive patterns between stops and fricatives, except for /t/. Most stops and fricatives gather together above the diagonal in Fig. 2a, indicating that the model tends to underestimate accuracy by $21-38 \%$ for segments other than $/ t /$ and $/ \delta /$, which were predicted quite accurately. However, the weighted model reduced the underestimation for stops at the expense of

\footnotetext{
${ }^{8}$ Note that the choice of a threshold value is a free parameter to maximize the predictions and the actual accuracy. See Park \& de Jong (2008) for more details.
} 
fricative accuracy estimation. The model predicted the perceptual accuracy for stops quite accurately $\left(R^{2}\right.$ for stops $\left.=0.92\right)$ while it completely fails to predict the accuracy for fricatives $\left(R^{2}=0.04\right.$, the underestimations range between $17 \%$ and $44 \%$ for fricatives). These results suggest that the Korean listeners' degree of L1 category dependence is different for stops and fricatives. In other words, the Korean listeners largely rely on L1L2 category mapping for identifying L2 stop categories, whereas they are less dependent on L1-L2 category mapping for identifying L2 fricatives and develop identification skills beyond the L1 skills.

*** Insert Figure 1 here.

*** Insert Figures $2 \mathrm{a}$ and $2 \mathrm{~b}$ here.

\subsection{2. '́CV position}

Figure 3 illustrates the bidirectional perceptual mapping between English and Korean categories in V́CV context. The perceptual category mapping is noisier in this position compared to that in VCV́ position (Figure 1), so more lines connecting categories appear in Figure 3. For example, there is only one path leading to predict the correct identification of English /p/ in VCV́ position: English /p/ to Korean /p/ to English /p/. However, there are two paths to consider in V́CV position: English /p/ to Korean $/ \mathrm{p}^{\mathrm{h}} /$ to English /p/, and English /p/ to Korean /p'/ to English /p/. To predict the L2 identification accuracies, we consider the sum of the likelihood of getting a particular English category from the paths through all involved Korean categories. Therefore, more paths in the category mapping, by themselves, do not automatically lead to poor predicted L2 
accuracy. Nevertheless, both models did predict lower identification accuracies for all segments, except for / $/$ in the weighted model, in V́CV position than in VCV́ position.

Figures $4 \mathrm{a}$ and $4 \mathrm{~b}$ plot the accuracy in the identification experiment (with the Roman/IPA labeling) for each of the eight target segments against predictions of the unweighted and the weighted models, respectively. The weighted model's predictions were made after subtracting 3.5 from the mean goodness ratings as in VCV́ position. We found a general correlation between predicted and actual accuracies in both models $\left(R^{2}=\right.$ 0.60 and 0.64 for the unweighted and the weighted models, respectively), suggesting that the Korean listeners' L2 identification is largely dependent on L1-L2 category mappings in V́CV position as well. In this position, however, neither the weighted nor the unweighted model clearly demonstrated different patterns between stops and fricatives, though both models underestimated the identification accuracy for English /f/ and / $/$ / by $9 \%$ to $19 \%$. One noticeably incorrect prediction of the model is that the Korean listeners would have difficulty in identifying English /b/. This prediction was due to the fact that the Korean listeners used the Korean lenis /p/ category for other English categories, such as English /v/, /ð/,/p/,/f/, and /d/, along with English /b/. Although the weighted model was better than the unweighted one by $5 \%$ in its prediction, both models failed to predict that Korean listeners would be good at identifying /b/ (71\%), which was the second best identification accuracy following that of $/ \mathrm{t} /(81 \%)$.

\footnotetext{
*** Insert Figure 3 here.

*** Insert Figures $4 \mathrm{a}$ and $4 \mathrm{~b}$ here.
} 


\subsubsection{VC position}

To investigate the influence of the coda stop release pattern, we examined all VC stimuli with and without the coda stop burst release. In Section 3.3.3.2, we present the results only on the labial stops, considering particularly differences due to the coda stop release patterns.

\subsubsection{All VC stimuli}

Figure 5 illustrates the bidirectional perceptual mapping between English and Korean categories in VC context. The first impression of this mapping is that there are more maps between English and Korean categories compared to the mappings in other prosodic contexts. This suggests that the Korean listeners had difficulty in deciding which Korean category labels they would use for English sounds and also that they did not agree with other listeners in their labeling choices. This mapping also includes some unique features to the VC context. First, "Others" (the symbol "?" in Figure 5) appears as one of the major labeling choices for English sounds in this position. This "Others" label was provided for the case when there were no appropriate Korean labels among 13 alternatives given for English stimuli. Thus, lines connected to "Others" indicate that the Korean listeners could not locate close L1-Korean categories to various English stimuli, including English /p/,/b/, /ð/, and /d/. Second, Korean /s/ is another Korean label unique to this position. The Korean listeners selected this label for English /t/, /d/, and / $\theta /$. Third, many lines connecting between English fricative categories and Korean $/ \mathrm{h} /$ are noticeable. The Korean listeners chose the Korean /h/ label for all English fricative and English stop /b/ stimuli at an above chance level. 
*** Insert Figure 5 here.

Figures $6 \mathrm{a}$ and $6 \mathrm{~b}$ plot the accuracy in the identification experiment (with the Roman/IPA labeling) for each of the eight target segments against predictions of the unweighted and the weighted models, respectively. Since overall mean goodness ratings were lower in this position we subtracted 1.5 from the mean goodness ratings to generate predictions with the weighted model, rather than the 3.5 threshold used for the other positions. Although there was a general correlation between predicted and actual accuracies in both models $\left(R^{2}=0.55\right.$ and 0.43 for the unweighted and the weighted models, respectively), such correlations were not as strong as in other prosodic contexts. Thus, neither the weighted nor the unweighted model demonstrated distinctive patterns between stops and fricatives as in V́CV position.

We cannot overlook the models' apparent failure to predict identification accuracies for English fricatives /f/ and /ð/; both models overestimated the Korean listeners' identification accuracy of English / / by at least 20\% (20\% and $28 \%$ in the unweighted and weighted models, respectively) and underestimated their identification accuracy of English /f/ by at least 34\% (37\% and 34\% in the unweighted and weighted models, respectively). The models predicted that the Korean listeners would identify English /ð/ at levels as good as English /p/, /b/, /v/, and / / /, since there are several paths leading to correct identification for English /ð/. As we can see in Figure 5, English /ð/ stimuli are connected to its intended category through Korean categories /p/, /h/, /L/, and "Others". Summing all these paths yields to high of a predicted accuracy. The underestimated 
accuracy for English /f/ was due to the fact that several English categories, such as English $/ \mathrm{p} /$ and $/ \theta /$, other than $/ \mathrm{f} /$ were also connected to Korean $/ \mathrm{p}^{\mathrm{h}} /$. Thus, the highly probable mapping from English $/ \mathrm{f} /$ to Korean $/ \mathrm{p}^{\mathrm{h}} /$ becomes less probable in the reverse mapping, resulting in somewhat poor predicted L2 identification accuracy.

Overall, both the predicted and the actually observed accuracies were low in this position. Both models' predicted accuracy for the English stimuli were between $17 \%$ and $40 \%$, except for $/ \mathrm{t} /(59 \%$ to $68 \%)$, and actually observed accuracies were between $2 \%$ and $33 \%$, except for $/ \mathrm{f} /(66 \%)$ and $/ \mathrm{t} /(74 \%)$. Nevertheless, the models showed the tendency to underestimate L2 identification accuracies; most circles appear above the diagonal line in Figures 6a and 6b.

*** Insert Figures $6 \mathrm{a}$ and $6 \mathrm{~b}$ here.

\subsubsection{Released labials vs. Unreleased labials}

In this section, we present whether the L1-based models can predict the learners' identification accuracy better if the release patterns of coda stops are considered. Since all coronal stop stimuli were released in VC position, we examined only labial stops. Figure $7 \mathrm{a}$ and $7 \mathrm{~b}$ plot the identification accuracy in the identification experiment for the labial stops against predictions of the unweighted and the weighted models, respectively. As in Section 3.3.3.1, we subtracted 1.5 from the mean goodness ratings for the predictions with the weighted model. Hollow and filled circles indicate the $/ \mathrm{p} /$ and $/ \mathrm{b} /$, respectively, combining the released and unreleased instances, which were presented in Section 3.3.3.1. Hollow and filled diamonds are released /p/ and /b/, respectively. Hollow and filled 
triangles represent unreleased $/ \mathrm{p} /$ and $/ \mathrm{b} /$, respectively. Comparing the combined $/ \mathrm{p} /$ and /b/ results, both models seem to predict the identification patterns for the released and unreleased $/ \mathrm{p} / \mathrm{s}$ and $/ \mathrm{b} / \mathrm{s}$ better, though the improvement is meager. The difference between the predictions and the identification accuracies were $5 \%$ and $8 \%$ for the combined $/ \mathrm{p} /$ and $/ \mathrm{b} /$, respectively. Such differences decreased to $1 \%$ for the released $/ \mathrm{p} /$ and $/ \mathrm{b} /$ with the unweighted model, and to about $1 \%$ and $7 \%$ for the unreleased $/ \mathrm{p} /$ and $/ \mathrm{b} /$ with both models. Nevertheless, the models did not show distinctive patterns between the released and the unreleased labial stops.

*** Insert Figures $7 \mathrm{a}$ and $7 \mathrm{~b}$ here.

\section{Discussion.}

\subsection{Mapping effects across prosodic contexts}

Our first question concerns the extent to which mapping patterns found in previous onset consonants generalize to the same consonants in other prosodic contexts, and then, if differences between "new" and "similar" sounds are found with these other prosodic contexts. The current data show a range of degree of difference between prosodic contexts. Mapping patterns found here for intervocalic consonants do differ extensively from those found previously with onset consonants in initial position (Park \& de Jong, 2008), though the degree of difference is modulated by the location of stress. For example, prevocalic English voiced stops mapped to two Korean categories, aspirated and lenis stops with the same place of articulation. However, these English stops mapped to a single Korean category, lenis stops, in the intervocalic contexts. Comparing mapping 
patterns between the two intervocalic contexts, noisier patterns are noticeable among the post-stressed intervocalic (V́CV) obstruents, indicating the effects of stress. For instance, English /p/ mapped to a single Korean category, Korean aspirated stops $/ \mathrm{p}^{\mathrm{h}} /$ in the prestressed intervocalic (VCV́) position, as it did in the pre-vocalic onset position (CV). However, it mapped to three Korean categories, Korean $/ \mathrm{p}^{\mathrm{h}} /, \mathrm{p} /$, and $/ \mathrm{p}$ '/ in the poststressed intervocalic position. Similar, noisier patterns are observed for the cases of English $/ \mathrm{d} /, \mathrm{f} /$, and $/ \theta /$. Hence, this portion of the data found here would generally conform to the expectations of an allophone-by-allophone mapping model.

The strong effect of stress found here lends some credence to allophone-by-allophone models, since the stress position differences are properties specific to English. While Korean listeners have been found to be quite good at identifying stress location (Altmann, 2006), stress effects are not found in Korean productions. The allophonic variation found in the English stimuli in the current study would be driven by variation in English production (e.g., longer lag VOTs of voiceless stops in VCV́ than in V́CV), rather than by expectations brought to the task by the Korean listeners. As noted in the introduction, Korean exhibits extensive allophonic variation between initial onsets and intervocalic position, but this allophonic variation in the L1 should affect both intervocalic contexts, and should not be affected by stress location from the L2. The current data suggest that the Korean listeners evaluate the pre-stress intervocalic stops with respect to the acoustic structure of what is produced (e.g., VOTs of voiceless stops), even though the consonants are situated in the intervocalic position, where the corresponding Korean consonants are different in the L1. 
Given the pre-stressed and post-stressed intervocalic patterns found here, we turn now to evaluate our ability to predict the identification accuracies from the mapping data. In the case of pre-stressed intervocalic consonants, the results found here closely resemble those found for initial onsets in Park \& de Jong (2008). Stops and fricatives differed with respect to the degree of fit between mapping predictions and actual identifications.

Identification accuracy for stops conforms closely to what is predicted from the mapping patterns; however, it is persistently higher than predicted for fricatives. This difference, in turn, is matched to an overall difference in goodness of fit between Korean labels and English stops and fricatives, such that stops are persistently rated as more similar to some Korean counterpart than fricatives. These two facts conform to the original contention of SLM that segments with a relatively close match to something in the L1 are entangled with that L1 category, while segments more distant from anything in the L1 will show appreciable development beyond that expected from the use of the L1 alone.

However, this difference between stops and fricatives is not found in the post-stressed context. This must be related to the difference in overall fit for stops and fricatives. The mean goodness ratings of modal responses for English stops were higher in the prevocalic initial and the pre-stressed intervocalic positions than in the post-stressed intervocalic position. For example, the goodness ratings for English voiceless stops were 6.00 or higher in the pre-vocalic initial and the pre-stressed intervocalic positions. However, none of the mean goodness ratings in the post-stressed intervocalic position was higher than 6.00 .

Interestingly, these observations concerning the difference between initial onset and pre-stress intervocalic vs. post-stressed intervocalic obstruents are reminiscent of the 
observations concerning the difference between voiceless and voiced stops in onset position in the previous study (Park \& de Jong, 2008). Park \& de Jong (2008) report that the L1 mapping (weighted) model could predict accuracy for both the voiced and voiceless stops. However, the voiceless and voiced stops differed in two ways. First, the overall fit for the voiced stops was intermediate between voiceless stops and fricatives and, second, both the predicted and the actual accuracies were relatively low. Similarly, in the post-stressed intervocalic position, predicted accuracies for all of the segments, except for $/ \mathrm{b} /$, are quite similar to what is actually found, and the predicted and observed accuracies are all somewhat low compared to those in other contexts. Thus, we suggest that the status of the post-stressed intervocalic obstruents is intermediate between "similar" and "new" L2 sounds as the case of prevocalic-initial voiced stops. That is, the effect of placing consonants in the post-stressed intervocalic context is to generally reduce their similarity with the L1 Korean consonants. This intermediate status approach agrees with the view that similarity is a gradient property rather than binary categories (e.g., Guion et al., 2000; Strange et al., 1998).

\subsection{Effects of neutralization}

A second, related, question has to do with the effect of position-specific neutralization processes. Three possibilities were outlined in the Introduction and summarized in Section 2.4. The first and the second possibilities would be those predicted by an allophone-by-allophone model. The first possibility is that the Korean listeners would treat English voiceless stops as "similar" sounds to the superficial output of the Korean process in codas. Thus, the L1 mapping models will predict somewhat high accuracy for 
English voiceless stops and underestimate accuracies for English voiced stops and all fricatives, which are "new" segments to the Koreans. The second possibility is similar to the first one, but it considers the release of English coda stops in the mapping. In this possibility, either voiceless English stops or both voiced and voiceless English stops will be similar to the neutralized stops in Korean if they are unreleased. Thus, the L1 mapping models will underestimate accuracies for released English stops as well as for all fricatives and predict higher accuracies for unreleased stops. The third possibility is that almost all English segments will be "new" sounds to Korean in coda (the "detuning" scenario, predicting high confusion among L1 segments in coda position). Then, the L1 category dependence models will systematically underestimate accuracies for most English sounds, and the overall predicted accuracies will be low in this position.

The results support the third possibility. ${ }^{9}$ The mapping model underestimated accuracies for almost all segments, though the rate of underestimation may not be large, except for /f/. In addition, the accuracies for English segments were lower in VC compared to other contexts. Overall difficulty of L2 identification is predicted from the L1 category dependence models; many branches in the mappings and the common appearance of "Others" (?) responses indicate that the Korean listeners' struggled to map all of the coda sounds to the L1, including the voiceless stop /p/. Frequently chosen "Others" responses in L2 labeling task also indicate overall difficulty of L2 identification.

The analyses for the released and unreleased coda labial stops do not give support either to the second possibility, the perception of the released obstruents in the following

\footnotetext{
${ }^{9}$ As one reviewer points out, the result for / $t$ / suggest the first possibility. The models accurately predict a high accuracy for /t/. Nevertheless, the overall results (i.e., overall underestimated accuracies of the models, low predicted accuracies, and frequently chosen "Others" responses for most segments) support for the third possibility more strongly.
} 
onset position due to perceptual epenthesis. All the observations made for coda segments, such as many branches in the mapping, a large portion of "Others" responses, etc., also held for the unreleased /p/ and /b/ as well. Although both models correctly predicted the identification accuracy within a $1 \%$ difference range for the unreleased $/ \mathrm{p} /$, the low mean goodness ratings and identification accuracies do not indicate these segments to be “similar" L2 segments. In other words, the mean goodness ratings and the identification accuracies did not distinguish the unreleased $/ \mathrm{p} /$ from other stimuli such as $/ \mathrm{v} /$ or $/ \theta /$. Note that the observations made for the unreleased labial stops were also true for the released labial stops. Further, a strong support would come from relatively high goodness ratings and identification accuracies for the released labial stops, if they were perceived in the following onset position due to perceptual epenthesis. None of these observations were found for the released labial stops. The identification accuracies were $23 \%$ and $33 \%$ for the released /p/ and /b/, respectively. These are much lower than the identification accuracies for /p/ (89\%) and /b/ (52\%) in CV position (Park \& de Jong, 2008). It is true that the mean goodness ratings of the most frequent Korean responses were relatively high for the released labial stops than for the unreleased counterparts. However, the overall goodness ratings were similar to each other for the released (3.84) and the unreleased labial stops (3.83), which were much lower than those for $/ \mathrm{p} /(6.15)$ and $/ \mathrm{b} /$ (5.13) in CV position (Park \& de Jong, 2008). All things considered, therefore, it is unlikely that the Korean listeners perceived released coda stops just as if they were in a following onset position.

Some explanation concerning the $/ \mathrm{s} /$ responses in codas is in order. For coronal stops $/ \mathrm{t} /$ and $/ \mathrm{d} /$, the Korean listeners chose /s/ at rates of $11 \%$ and $16 \%$, respectively. This /s/ 
appearance also happens in loanword adaptation patterns of English words ending with /t/ and /d/. For example, English words pyramid and internet will be borrowed as $/ \mathrm{p}^{\mathrm{h}}$ iramis/ (피라밋) and /int ${ }^{\mathrm{h}}$ ones/ ( 인터넷) in standard Korean orthography. One main reason for this is due to a matter internal to the morpho-phonology of Korean nouns (See Davis \& Kang, 2006 for further discussion). In modern Korean, all coronal stem-final obstruents, including /s/, neutralize to the coronal stop [t] in coda position. However, /s/ is realized before a vowel initial suffix (e.g., [int ${ }^{\mathrm{h}}$ ənet] in isolation but [int ${ }^{\mathrm{h}}$ ənes-il] 'internet + accusative case marker). ${ }^{10}$ In addition, the orthographic distributions of $/ \mathrm{t} / \mathrm{and} / \mathrm{s} /$ in coda position are likely to encourage the adoption of /s/ for borrowing coronal stops. Previous studies (Albright, 2008; Ito, 2010; Jun, 2010; Jun \& Lee, 2007; Kang \& Kim, 2004 cited by Jun, 2010; Sohn, 2001) point out that /s/ is the most frequent word final obstruent of Korean nouns, whereas /t/ occurs very rarely. For instance, Albright (2008) reports that among the 8,108 obstruent-final nouns in the Sejong Project corpus ${ }^{11}$ there are 375 /s/ending nouns compared to only $1 / \mathrm{t} /$-ending noun. Such an L1 orthographic influence is also shown by the fact that fortis labels were rarely chosen for English categories in coda. In the same study, Albright (2008) reports that there was no instance of nouns ending with $/ \mathrm{p} \%$ or $/ \mathrm{t} \%$

The peculiar behavior of /f/ also bears some note. The mapping models considerably underestimated the identification accuracy for /f/ because the major response label for English /f/ (i.e., Korean aspirated $/ \mathrm{p}^{\mathrm{h}} /$ ) are shared by other English categories. In all

\footnotetext{
${ }^{10}$ In Middle Korean starting from later in $16^{\text {th }}$ and $17^{\text {th }}$ century, most $/ t /$-final nouns had been reanalyzed as having a final $/ \mathrm{s} /$. By the $18^{\text {th }}$ century, the historical change had been completed and the final obstruent of such words was phonologically categorized as $/ \mathrm{s} /$, though it was phonetically categorized as [t]. Some examples of such words are pus 'writing brush', kas 'hat', and mos 'nail' (Ito, 2010; Ko, 1989; Kang, 2003b).

${ }^{11} \mathrm{http}: / /$ sejong.or.kr
} 
prosodic contexts (even in CV), the Korean listeners' accuracy for /f/ is the highest among all fricatives. In other words, the models failed to predict the high accuracy for /f/ in all contexts. This might be related to the speech signal itself; /f/ is perceptually more salient than the other fricatives tested in this study. Thus, the listeners may depend less on L1 categories in identifying/f/. A second possibility, suggested in de Jong, Hao, Park, \& Sibert (2008), may be that the accuracy for /f/ is inflated by a persistent bias toward the /f/ response category. As noted in de Jong et al. (2008), for some reason, the /f/ category is often noted in the teaching of English to Koreans as being a particular feature of English productions, which may highlight the category's salience in tasks such as the current one, which emphasize the difference between the native and the learned language.

Finally, there is one case in which the mapping model actually over-estimates L2 identification accuracy, a pattern which is not predicted by the SLM model. For English $/ \delta /$ in coda position, the models overestimated the accuracy, apparently because there are several paths allowing the correct identification of this sound. Notice that paths used in the prediction are Korean categories /p/, /h/, /L/, and "Others" (?), which we may consider identification errors for English /ð/. It could be that such weak mappings make the $\mathrm{L} 1$ categories unhelpful for dealing with the L2 consonant. Further, with respect to developing a new category, English / $/$ / is very rare in coda position, and the acoustic signal is weak. For example, consonant duration of $/ \delta /$ is shorter than that of $/ \theta /$, and the noise strength is very low. This, coupled with the coda positioning, which adds a further barrier to the Korean perceptual system, makes this case of /ð/ the worst case scenario for learners. All things considered, it is quite remarkable that, with this one exception, this is the only case in the entire database used here and that in Park \& de Jong (2008) in which 
the mapping model over-predicted accuracies, perhaps indicating a systematic degree of learning success among the Korean learners overall.

\section{Conclusions}

The results from the current and Park \& de Jong (2008)'s studies suggest at least four main points concerning issues addressed by the SLM framework. First, the distinction between "new" and "similar" categories in the SLM operates in perceptual learning of L2 categories as in production, though the original SLM is a production model rather than a perceptual one. Second, similarity is a gradient property rather than dichotomous, though L2 categories having the intermediate status between "similar" and "new" sounds may pattern like "similar" categories. This suggests that "somewhat similar" L2 sounds remain more problematic than "similar" sounds throughout the course of L2 perceptual learning. Learners' L2 identification performance is lower for "somewhat similar" sounds than for "similar" sounds, and not much progress is expected due to heavy reliance on L1 categories in perceiving "somewhat similar" L2 sounds. Third, the unit of L2 perceptual learning is not likely to be segments generalizing across prosodic locations. Rather, it appears to concern either position-specific allophones as generally assumed in the SLM (Flege, 1995) or features generalizing across prosodic locations (e.g., manner of articulation as in de Jong, Silbert, \& Park, 2009). Fourth, despite the specificity of consonants by position found in the current results, segment-general complete neutralization processes in L1, such as coda neutralization in Korean (Kim \& Jongman, 1996), may put all L2 segments at that position as "new" sounds rather than just reducing the number of "similar" sounds. Such a situation will pose a significant challenge in L2 
sound learning in which a learner should learn to suppress L1 processes (Darcy, Park, \& Yang, 2015).

The current and Park \& de Jong (2008)'s studies also demonstrate the usefulness of the L1-based models in quantifying the degree of involvement of L1 categories in perceiving L2 categories. Both unweighted and weighted models performed well in predicting the identification accuracies for L2 segments. However, the weighted model was more successful at showing the contrast in "newness" of L2 sounds, if there is such distinction in a given prosodic context. This suggests that we need to consider goodnessof-fit judgments along with response proportions in an L2 identification task.

Lastly, the current study's and Park \& de Jong (2008)'s category mapping data present only a snap shot of the L2 learning process. Both studies are cross-sectional rather than longitudinal and they examine only perceptual identification from the perspective of L1Korean learners of English. Thus, further research is necessary to understand the role of the similarity in L2 phonological learning. Pairing of Korean and English is very appropriate for this type of research since there is no confusion at the orthographic level between these two languages. We can get a measurement of the degree of similarity between L1 and L2 categories in an objective manner, using the orthographic classification technique and goodness-of-fit judgments. Then, we can directly examine how categories differing in similarity develop over time. We currently are conducting a longitudinal study on L1-English learners of Korean to assess how the mapping and L2 identification systems develop over time. We hope to provide additional data from this study in near future, to help us forward to the understanding of L2 phonological learning processes. 


\section{Acknowledgements}

This work is supported by NSF (Grant \#BCS-04406540; "Prosody in Cross-language Production and Perception"). We would like to express appreciation to Mi-Hui Cho for help in collection of the data and to Kyoko Nagao and Noah Silbert for their work on the design and processing of the data. We are also thankful for copious and valuable comments from Erika Levy and three anonymous reviewers. 


\section{Appendix A. Instructions and Answer sheets for the mapping and identification}

\section{experiments}

1. Instructions and answer sheet for the mapping experiment

$$
\begin{aligned}
& \text { 여러분은 이제 영어 화자가 녹음한 일련의 단어들을 듣게 될 것입니다. 먼저 각 } \\
& \text { 단어의 번호를 들은 후에, } 1 \text { 음절 혹은 } 2 \text { 음절의 단어들을 듣게 될 것입니다 (이 } \\
& \text { 단어들은 실제 영어 단어가 아닙니다). 이 각각의 단어들 속에서 듣게 되는 } \\
& \text { 자음이 무엇인지 보기 중에서 골라주십시오. }
\end{aligned}
$$

(You will hear a series of items spoken by native speakers of English. For each item, you will hear a number followed by a one or two syllable word (these words are not real English words.) Please identify the consonant you hear among the alternatives.)

$$
\begin{aligned}
& \text { 만약 듣게 되는 단어 속의 자음이 보기 중에서 없으면, 무엇을 들었는지 그 외( ) } \\
& \text { 에 한글로 표기해 주십시오. }
\end{aligned}
$$

(If the choices do not include the consonant that you hear, you may write what you heard in the space marked other ( ) in Korean orthography.)

$$
\begin{aligned}
& \text { 자음을 보기 중에서 고르신 다음, 자신이 고른 답이 들은 자음과 얼마나 비슷한 } \\
& \text { 지 보기의 옆에 있는 번호에 표기해 주십시오. 가령 여러분이 고른 자음이 } \\
& \text { 여러분이 들은 자음과 전혀 비슷하지 않으면, “1”에 표기해 주십시오. 하지만 } \\
& \text { 여러분이 고른 자음과 들은 자음이 아주 똑같은 자음이라고 생각하면, “7” 에 } \\
& \text { 표기해 주십시오. }
\end{aligned}
$$

(After identifying the consonant that you heard among the alternatives, indicate how similar your choice and the consonant you heard are by circling a number to the right of the alternatives. For example, circle " 1 " if the consonant you chose is not similar to the consonant you heard at all. However, circle "7" if you think that the consonant you chose and the consonant you heard are exactly the same.)

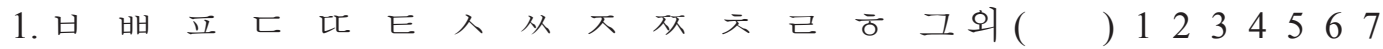

$$
\begin{aligned}
& \left(\begin{array}{lllllllllllll}
/ \mathrm{p} & \mathrm{p}^{\prime} & \mathrm{p}^{\mathrm{h}} & \mathrm{t} & \mathrm{t}^{\prime} & \mathrm{t}^{\mathrm{h}} & \mathrm{s} & \mathrm{s}^{\prime} & \mathrm{c} & \mathrm{c}^{\prime} & \mathrm{c}^{\mathrm{h}} & \mathrm{L} & \mathrm{h} / \text { others }
\end{array}\right)
\end{aligned}
$$

2. Instructions and answer sheet for the identification experiment

You will hear a series of items spoken by native speakers of English. For each item, you will hear a number followed by a one or two syllable nonsense word. For each nonsense word, please identify the consonant you hear by circling the appropriate symbol. If you do not find a symbol for the consonant that you hear, you may write the appropriate English consonant in the space marked other ( ). The symbols that you may choose from are: 


$\begin{array}{ll}\text { symbol } & \text { description } \\ \mathrm{p} & \text { as in the words pit, apple, and stop } \\ \mathrm{t} & \text { as in the words ten, beauty, and cat } \\ \mathrm{f} & \text { as in the words fan, beautiful, and half } \\ \Theta & \text { as in the words think, math, and thank you } \\ \mathrm{s} & \text { as in the words salt, list, and pass } \\ \mathrm{r} & \text { as in the words rock, hearing, and cover } \\ \mathrm{w} & \text { as in the words wood, towel, and cow } \\ \mathrm{h} & \text { as in the words } \underline{\text { happy, ahead, and hand }}\end{array}$

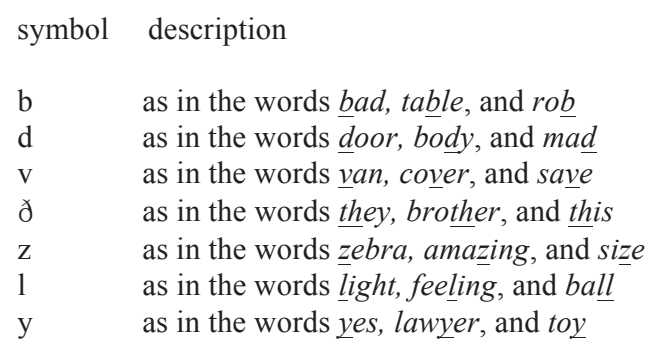

After identifying the consonant that you heard, indicate how certain you are that you have chosen the appropriate symbol by circling a number to the right of the consonant symbols. The number 1 indicates that you are not confident that you have chosen the appropriate symbol for the consonant that you heard (you are just guessing). The number 7 indicates that you are very confident that you have chosen the appropriate symbol for the consonant that you heard.

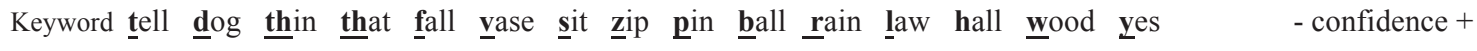

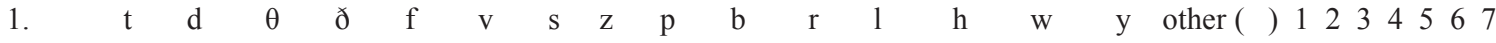

\section{Appendix B. Step-by-step predicted accuracy calculations in L1-based models}

To explain how we calculated the predicted accuracy, we will use the predicted accuracy for English /d/ in VCV́ context (See Table III). The unweighted model does not consider the mean goodness ratings in the predicted accuracy calculation. The formula is the following (Park \& de Jong, 2008, p. 709):

\section{(1) Prediction of accuracy based on the confusion between L1 and L2}

Probability of accuracy where L2 Category A is perceived as L2 Category A $=\sum$ (probability of L2 category A being perceived as L1 category X $\times$ probability of L1 category $\mathrm{X}$ being associated with L 2 category A)

We need two probabilities to calculate the predicted accuracy: the L2-to-L1 probability and the L1-to-L2 probability. The L2-to-L1 probability is the proportion of L1 category for an L2 category of interest (i.e., the results from the mapping experiment). Regarding the English /d/ case, there are two Korean labels chosen for English /d/, resulting in two L2-to-L1 probabilities: 0.95 for Korean lenis /t/ and 0.03 for Korean fortis $/ \mathrm{t} \%$. To calculate the L1-to-L2 probability, we have to consider all the L2 cases for which those L1 categories are used. There are 4 cases Korean lenis / $\mathrm{t} /$ labels are used for: English /b/ (6\%), /d/ (95\%), /ð/ (76\%), and /v/ (7\%). When we add up all of the cases in which Korean lenis $/ \mathrm{t} /$ is used, only about $52 \%(0.516=0.95 \div(0.06+0.95+0.76+$ $0.07)$ ) are the cases of Korean lenis / $\mathrm{t} /$ associated with English $/ \mathrm{d} /$. If we follow the same step for Korean $/ \mathrm{t}$ '/ category, we get about $9 \%(0.093=0.03 \div(0.01+0.03+0.24+0.03$ $+0.01)$ ). When we use these probabilities, the predicted accuracy for English $/ \mathrm{d} / \mathrm{using}$ the Korean lenis $/ \mathrm{t} /$ category is about $50 \%(0.494=0.95 \times 0.52)$ and that using Korean fortis $/ \mathrm{t}$ '/ category is about $3 \%(0.027=.03 \times 0.09)$. Thus, the total predicted accuracy is $52 \%(0.521=0.494+0.027)$. Check this predicted accuracy in Figure $2 \mathrm{a}$. 
The weighted model also uses two probabilities, the L2-to-L1 probability and the L1to-L2 probability, to calculate the predicted accuracy, and the way to get the L2-to-L1 probability is the same as in the weighted model. Only difference will be found in the way to calculate the L1-to-L2 probability. The following is the formula to calculate the L1-to-L2 probability in the weighted model (Park \& de Jong, 2008, p710):

\section{(2) Weighted proportion of L2 category X in L1 category $Y$}

Proportion of L2 category $\mathrm{X}$ in $\mathrm{L} 1$ category $\mathrm{Y}=$ probability of $\mathrm{L} 2$ category $\mathrm{X}$ is perceived as L1 category $\mathrm{Y} \times$ (its mean similarity rating score - lower threshold $)\} / \sum$ \{probability of all L2 categories associated with L1 category $\mathrm{Y} \times$ (its mean similarity rating score - lower threshold)\}

Note that the formula above does not specify the value for the lower threshold. The use of threshold is to increase of the strength of differences in the goodness ratings. Thus, the choice of threshold is somewhat arbitrary. Also note that we ignore the instances of percentage labeling lower than $7.69 \%$ (the chance level) in the calculation with the weighted model; we sacrifice some minor portion of data to increase the strength of the weighting. To explain the calculation procedure, however, we will not exclude instances of percentage labeling lower than $7.69 \%$ and will use 2.4 as the lower threshold (rather than 3.5 , which was actually used for VCV́ context throughout the paper). The following shows the calculation for the L1-to-L2 probabilities regarding the English /d/ case we've been using in the unweighted model above.

L1/t/-to-L2/d/: $0.578=(0.95 \times 3.16) \div\{(0.06 \times 2.10)+(0.95 \times 3.16)+(0.76 \times 2.59)+$ $(0.07 \times 1.30)\}$

L1/t'/-to-L2/d/: $0.132=(0.03 \times 2.10) \div\{(0.01 \times 0.01)+(0.03 \times 2.10)+(0.24 \times 1.42)+$ $(0.03 \times 2.35)+(0.01 \times 0.01)\}$

The predicted accuracies for English /d/ using the two Korean accuracies are the following:

Through Korean $/ \mathrm{t} /: 0.95 \times 0.578=0.549$

Through Korean /t'/: $0.03 \times 0.132=0.004$

Thus, the weighted model predicts about $53 \%(0.553=0.549+0.004)$ accuracy rate for English /d/. Note that this prediction is different from the prediction in Figure $2 \mathrm{~b}$ since more portions of the data and a different lower threshold value were used to illustrate the calculation procedure. 


\section{References}

Albright, A. (2008). Explaining universal tendencies and language particulars in analogical change. In J. Good (Ed.), Language universals and language change (pp. 144-181). Oxford: Oxford University Press.

Altmann, H. (2006). The perception and production of second language stress: A cross linguistic experimental study. Doctoral dissertation, University of Delaware.

Best, C. T, McRoberts, G. W., \& Goodell, E. (2001). Discrimination of non-native consonant contrasts varying in perceptual assimilation to the listener's native phonological system. Journal of the Acoustical Society of America, 109, 775-794.

Best, C. T., McRoberts, G. W., \& Sithole, N. M. (1988). Examination of perceptual reorganization for nonnative speech contrasts: Zulu click discrimination by Englishspeaking adults and infants. Journal of Experimental Psychology: Human Perception and Performance, 14, 345-360.

Best, C. T. \& Tyler, M. D. (2007). Nonnative and second-language speech perception. In O.-S. Bohn and M. J. Munro (Eds.), Language experience in second language speech learning: In honor or James Emil Flege (pp. 13-34). Amsterdam: John Benjamins.

Cebrian, J. (2000). Transferability and productivity of L1 rules in Catalan-English interlanguage. Studies in Second Language Aquisition, 22, 1-26.

Cebrian, J. (2006). Experience and the use of non-native duration in L2 vowel categorization. Journal of Phonetics, 34, 372-387.

Chang, C. \& Mishler, A. (2012). Evidence for language transfer leading to a perceptual advantage for non-native listeners. Journal of the Acoustical Society of America, 134, $2700-2710$. 
Cho, M. \& Lee, S. (2007). Category matching between English and Korean consonants in different prosodic environments. English Language and Literature, 53, 731-753.

Cho, T., Jun, S.-A., \& Ladefoged, P. (2002). Acoustic and aerodynamic correlates of Korean stops and fricatives. Journal of Phonetics, 30, 193-228.

Davis, S. \& Kang, H.-S. (2006). English loanwords and the word final [t] problem in Korean. Language Research, 42, 253-274.

Darcy, I., Park, H., \& Yang, C.-L. (2015). Individual difference in L2 acquisition of English phonology: The relation between cognitive abilities and phonological processing. Learning and Individual Differences, 40, 63-72.

de Jong, K. J., Hao, Y.-C., \& Park, H. (2009). Evidence for featural units in the acquisition of speech production skills: Linguistic structure in foreign accent. Journal of Phonetics, 37, 357-373.

de Jong, K. J., Hao, Y.-C., Park, H., \& Silbert, N. H. (2008). The '[+English]' effect in acquisition of English as a second language: Novel category biases in second language perception and production. Journal of the Acoustical Society of America, 123, 3332. de Jong, K. J., Silbert, N. H., \& Park, H. (2009). Generalization across segments in second language consonant identification. Language Learning, 59, 1-31.

Eckman, F. R. (1977). Markedness and the contrastive analysis hypothesis. Language Learning, 27, 315-330.

Eckman, F. R. (1991). The structural conformity hypothesis and the acquisition of consonant clusters in the interlanguage of ESL learners. Studies in Second Language Acquisition, 13, 23-41.

Eckman, F. R. \& Iverson, G. K. (1994). Pronunciation difficulties in ESL: Coda 
consonants in English interlanguage. In M. Yavas (Ed.), First and second language phonology (pp. 251-265). San Diego, CA: Singular.

Flege, J. E. (1987). The production of new and similar phones in a foreign language:

Evidence for the effect of equivalence classification. Journal of Phonetics, 15, 47-65.

Flege, J. E. (1991). The interlingual identification of Spanish and English vowels:

Orthographic evidence. Quarterly Journal of Experimental Psychology, 43, 701-731.

Flege, J. E. (1995). Second language speech learning: Theory, findings, and problems. In W. Strange (Ed.), Speech perception and language experience: issues in crosslanguage research (pp. 233-277). Baltimore, MD: York Press.

Flege, J. E. (2002). Interaction between the native and second-language phonetic system. In P. Burmeister, T. Piske, and A. Rohde (Eds.), An integrated view of language development: Papers in honor of Henning Wode (pp. 217-244). Trier:

Wissenschaftlicher Verlag Trier.

Guion, S. G., Flege, J. E., Akahane-Yamada, R., \& Pruitt, J. C. (2000). An investigation of current models of second language speech perception: The case of Japanese adults' perception of English consonants. Journal of the Acoustical Society of America, 107, 2711-2724.

Guion, S. G. \& Pederson, E. (2007). Investigating the role of attention in phonetic learning. In O.-S. Bohn \& M. J. Munro (Eds.), Language experience in second language speech learning: In honor or James Emil Flege (pp. 57-77). Amsterdam: John Benjamins.

Han, J.-I. (1996). The phonetics and phonology of "tense" and "plain" consonants in Korean. Ph. D. dissertation, Cornell University. 
Han, M. -S., \& Weitzman, R. S. (1970). Acoustic Features of Korean /P, T, K/, /p, t, k/ and $/ \mathrm{p}^{\mathrm{h}}, \mathrm{t}^{\mathrm{h}}, \mathrm{k}^{\mathrm{h}} /$. Phonetica, 22, 112-128.

Ito, C. (2010). Analogy and lexical restructuring in the development of nominal inflection from Middle to Contemporary Korean. Journal of East Asian Linguistics, 19, 357-383.

Iverson, P., Kuhl, P., Akahane-Yamada, R., Diesch, E., Tohkura, Y., Kettermann, A., \& Siebert, C. (2003). A perceptual interference account of acquisition difficulties for non-native phonemes. Cognition, 87, B47-B57.

Jang, M. (2014). Perception of English consonants in different prosodic positions by Korean learners of English. Phonetic and Speech Sciences, 6, 11-19.

Jun, J.-H. (2010). Stem-final obstruent variation in Korean. Journal of East Asian Linguistics, 19, 137-179.

Jun, J.-H. \& Lee, J.-H. (2007). Multiple stem-final variants in Korean native nouns and loanwords. Eoneohag, 47, 159-187

Jun, S.-A. (1994). The status of the lenis stop voicing rule in Korean. In Y.-K, KimRenaud (Ed.), Theoretical Issues in Korean linguistics (pp.101-114). Stanford: CSLI.

Kabak, B. \& Idsardi, W. J. (2007). Perceptual distortions in the adaptation of English consonant clusters: Syllable structure or consonantal contact constraints? Language and Speech, 50, 23-52.

Kagaya, R. (1974). A fiberscopic and acoustic study of the Korean stops, affricates and fricatives. Journal of Phonetics, 2, 161-180.

Kang, B.-M. \& Kim, H.-G. (2004). Frequency analysis of Korean morpheme and word usuage 2 [hankwuke hyengtayso mich ehwi sayong pintouy pwunsek 2]. Seoul: Institute of Korean Culture, Korea University. 
Kang, K.-H. \& Guion, S. G. (2008). Clear speech production of Korean stops: Changing phonetic targets and enhancement strategies. Journal of the Acoustical Society of America, 124, 3909-3917.

Kang, Y. (2003a). Perceptual similarity in loanword adaptation: English postvocalic word-final stops in Korean. Phonology, 20, 219-273.

Kang, Y. (2003b). Sound Changes Affecting Noun-Final Coronal Obstruents in Korean. In W. McClure (Ed.), Japanese/Korean Linguistics 12 (pp.128-139). Stanford: CSLI. Kang, Y. (2014). Voice Onset Time merger and development of tonal contrast in Seoul Korean stops: A corpus study. Journal of Phonetics, 45, 76-90.

Kim, C.-W. (1965). On the autonomy of the tensity feature in stop classification (with special reference to Korean stops). Word, 21, 339-359.

Kim, H.-S. \& Jongman, A. (1996). Acoustic and perceptual evidence for complete neutralization of manner of articulation in Korean. Journal of Phonetics, 24, 295-312.

Kim, M.-R. (2012). The [voice] system of Korean stops revisited with special reference to the aspirated-lax merger. Studies in Phonetics, Phonology and Morphology, 18, 211-243.

Keating, P. (1984). Phonetic and phonological representation of stop consonant voicing, Language, 60, 286-319.

Ko, K.-M. (1989). Explaining the noun-final change $\mathrm{t}>\mathrm{s}$ in Korean. Eoneohag, 11, 3-22. Ladefoged, P. \& Johnson, K. (2015). A course in phonetics. $7^{\text {th }}$ ed. Stamford: Cengage Learning.

Lengeris, A. (2009). Perceptual assimilation and L2 learning: Evidence from the perception of Southern British English vowels by native speakers of Greek and 
Japanese. Phonetica, 66, 169-187.

Lisker, L. \& Abramson, A. (1964). A cross-language study of voicing in initial stops: Acoustical measurements. Word, 20, 384-422.

Major, R. C. \& Faudree, M. C. (1996). Markedness universals and the acquisition of voicing contrasts by Korean speakers of English. Studies in Second Language Acquisition, 18, 69-90.

McAllister, R., Flege, J. E., \& Piske, T. (2002). The influence of L1 on the acquisition of Swedish quantity by native speakers of Spanish, English and Estonian. Journal of Phonetics, 30, 229-258.

Park, H. \& de Jong, K. J. (2008). Perceptual category mapping between English and Korean prevocalic obstruents: Evidence from mapping effects in second language identification skills. Journal of Phonetics, 36, 704-723.

Pederson, E. \& Guion-Anderson, S. (2010). Orienting attention during phonetic learning facilitates learning. Journal of the Acoustical Society of America, 127, EL54-EL59.

Schmidt, A. M. (1996). Cross-language identification of consonants. Part 1. Korean perception of English. Journal of the Acoustical Society of America, 99, 3201-3211.

Shin, J.-Y. \& Cha, J.-E. (2003). The sound system of Korean: For the groundwork of the Korean phonology research [urimal soriui chegye: gukeo eumullon yeonguui gichoreul wihayeo]. Seoul: Hankookmunwhasa.

Silva, D. (1991). A prosody-based investigation into the phonetic of Korean stop voicing. In S. Kuno, I.-H. Lee, J. Whitman, J. Maling, Y.-S. Kang, \& Y.-J. Kim (Eds), Harvard Studies in Korean Linguistics IV (pp.181-195). Seoul, South Korea: Hanshin Publishing Company. 
Silva, D. (1992). The phonetics and phonology of stop lenition in Korean. Ph. D. dissertation, Cornell University.

Sohn, H.-M. (1999). The Korean language. Cambridge, UK: Cambridge University Press.

Sohn, H.-S. (2001). Optimization of word-final coronals in Korean loanword adaptation. In Fery, C., Green, A.D., \& van de Vijver, R. (Eds.), Proceedings of HILP5 (pp.159177), University of Potsdam.

Strange, W., Akahane-Yamada, R., Kudo, R., Trent, S. A., Nishi, K., \& Jenkins, J. J. (1998). Perceptual assimilation of American English vowels by Japanese listeners. Journal of Phonetics, 26, 311-344. 
Tables

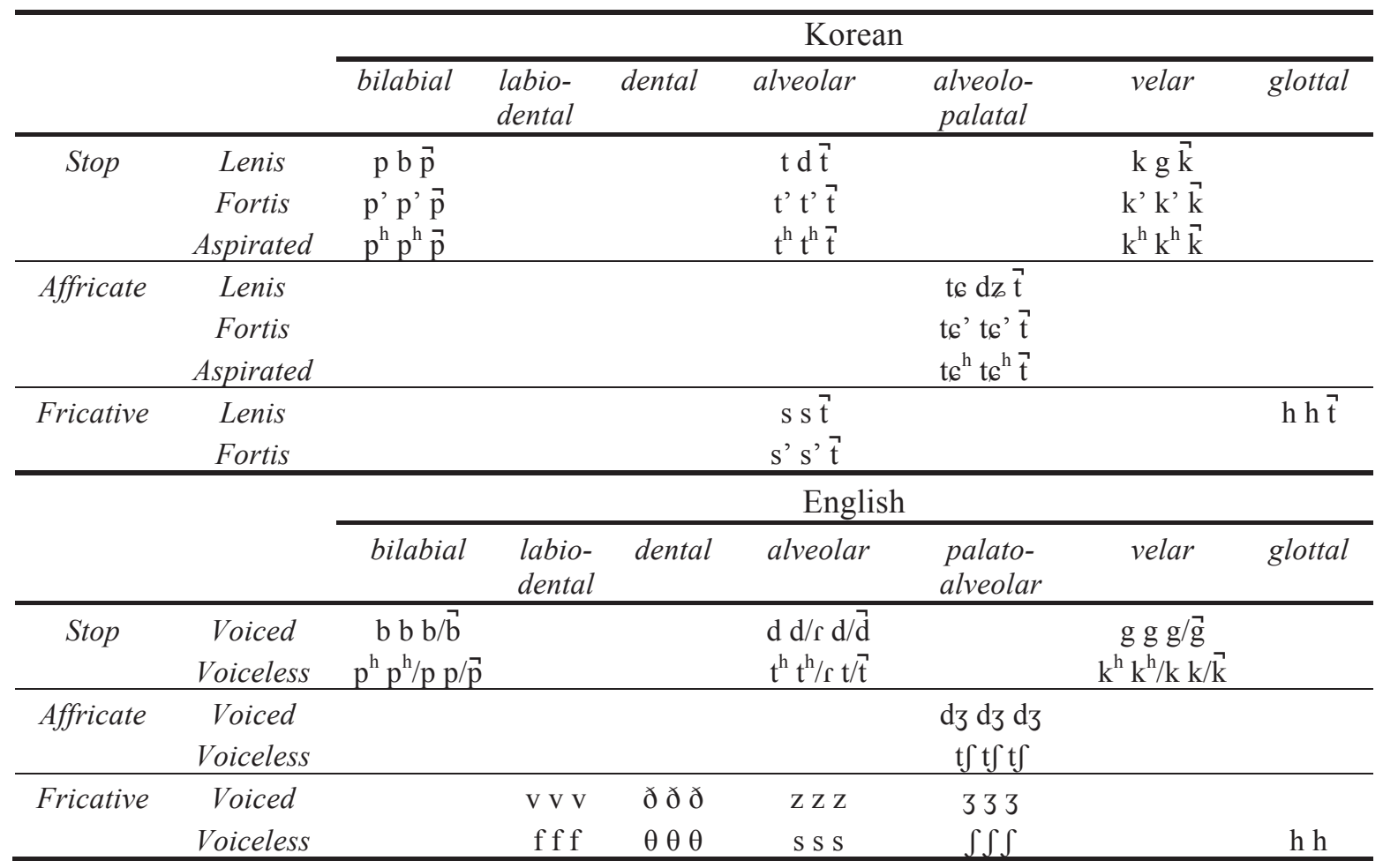

Table 1. Inventories of obstruent allophones in Korean and English

Note: In each cell, allophones in three prosodic contexts, i.e., onset, intervocalic, and coda, are shown. For example, " $p$ b $\vec{p}$ " for the Korean lenis bilabial stops indicate that [p], $[\mathrm{b}]$, and $[\overrightarrow{\mathrm{p}}]$ appear in onset, intervocalic, and coda positions, respectively. Only singleton allophones (rather than the ones in consonant clusters, such as $/ \mathrm{p} / \mathrm{in} / \mathrm{sp} /$ cluster) are presented. When there are variants, “/” is used. For instance, $b / b$ in coda position of English voiced bilabial stop indicates that both released and unreleased /b/ can occur in this position. English intervocalic allophones are listed without mentioning stress location explicitly, except for voiceless stops. For the voiceless stops, the first variant is the prestressed variant, and the second the post-stressed one. $/ \mathrm{h} /$ does not appear in coda position in English; thus, there are only two allophones shown for English voiceless glottal fricative. 


\begin{tabular}{cccc}
\hline \multirow{4}{*}{ Stops } & & English & \\
\cline { 2 - 4 } & Voiced & $/ \mathrm{b} /$ & Coronal \\
\hline \multirow{2}{*}{ Non-sibilant Fricatives } & Voiceless & $/ \mathrm{p} /$ & $/ \mathrm{d} /$ \\
& Voiced & $/ \mathrm{v} /$ & $/ \mathrm{t} /$ \\
\hline \multirow{2}{*}{ Syllabic context } & Voiceless & $/ \mathrm{f} /$ & $/ \theta /$ \\
& VCV́ & abá, apá, avá, afá & adá, atá, aðá, a $\theta$ á \\
& VCV & ába, ápa, áva, áfa & ába, ápa, áva, áfa \\
& VC & ab, ap, av, af & ad, at, að, a $\theta$ \\
\hline
\end{tabular}

Table 2. Corpus Description in the Current Study

Note: VCV́ = pre-stressed intervocalic consonant; V́CV = post-stressed intervocalic consonant; $\mathrm{VC}=$ post-vocalic word final consonant 


\begin{tabular}{|c|c|c|c|c|c|c|c|c|}
\hline \multirow[b]{2}{*}{ Korean } & \multicolumn{8}{|c|}{ English consonants } \\
\hline & $/ \mathrm{p} /$ & $/ \mathrm{b} /$ & $/ \mathrm{t} /$ & $/ \mathrm{d} /$ & $/ \theta /$ & $/ \mathrm{d} /$ & $\mid \mathrm{f} /$ & $/ \mathrm{v} /$ \\
\hline$/ \mathrm{p} /$ & & $91(5.72)$ & & & & $10(5.44)$ & $1(5.50)$ & $74(5.06)$ \\
\hline$/ \mathrm{p} /$ & $2(5.33)$ & & & & $7(5.45)$ & & $17(4.41)$ & $3(4.20)$ \\
\hline$/ \mathrm{p}^{\mathrm{h}} /$ & $89(6.00)$ & $1(6.50)$ & & & $6(4.90)$ & & $66(4.52)$ & $6(4.20)$ \\
\hline$/ \mathrm{t} /$ & & $6(4.50)$ & & $95(5.56)$ & & 76 (4.99) & & $7(3.70)$ \\
\hline$/ \mathrm{t}^{\prime} /$ & & & $1(2.50)$ & $3(4.50)$ & $24(3.82)$ & & $3(4.75)$ & $1(2.50)$ \\
\hline$/ \mathrm{t}^{\mathrm{h}} /$ & $3(5.60)$ & & $96(6.24)$ & & $1(5.50)$ & & & \\
\hline$/ \mathrm{L} /$ & & & & & & $9(4.40)$ & & $3(4.50)$ \\
\hline$/ \mathrm{s} /$ & & & & & $6(4.60)$ & & & \\
\hline$/ \mathrm{s}^{\prime} /$ & & & & & 49 (4.56) & & $6(3.10)$ & $1(5.50)$ \\
\hline$/ \mathrm{t}_{6} /$ & & & & & & $1(4.00)$ & & \\
\hline$/ \mathrm{t}^{\prime} /$ & & & & & & & & \\
\hline$/ \mathrm{t}^{\mathrm{h}} /$ & & & & & & & & \\
\hline$/ \mathrm{h} /$ & $3(6.20)$ & & & & $4(4.50)$ & & $5(5.00)$ & $1(3.00)$ \\
\hline Others & & & & & & $2(4.67)$ & & $2(6.33)$ \\
\hline
\end{tabular}

Table 3. Matrix showing percentage labeling of English pre-stressed intervocalic (VCV) consonants with Korean consonants and their mean goodness ratings. Judgments totaling less than $1 \%$ are not shown. Judgments not exceeding the chance level (7.69\%) are displayed in grey. Percentages and the mean goodness ratings are rounded to the nearest whole number and to the nearest hundredth, respectively. Each stimulus had approximately 160 tokens ( 4 talkers $\times 40$ listeners) for the analysis. Similarity ratings were on a gradient scale from 1 to $7(7=$ exactly like Korean). Modal responses are marked in bold. 


\begin{tabular}{|c|c|c|c|c|c|c|c|c|}
\hline \multirow[b]{2}{*}{ Korean } & \multicolumn{8}{|c|}{ English consonants } \\
\hline & $/ \mathrm{p} /$ & $/ \mathrm{b} /$ & $/ \mathrm{t} /$ & $/ \mathrm{d} /$ & $/ \theta /$ & /ठ/ & $\mid \mathrm{f} /$ & $/ \mathrm{v} /$ \\
\hline$/ \mathrm{p} /$ & $17(4.88)$ & 87 (5.62) & & $10(4.75)$ & $6(5.70)$ & $28(4.64)$ & $18(4.96)$ & $82(5.34)$ \\
\hline$/ \mathrm{p} /$ & $12(4.00)$ & & & & $9(4.73)$ & & $11(4.35)$ & $1(4.50)$ \\
\hline$/ \mathrm{p}^{\mathrm{h}} /$ & $51(5.04)$ & & & & $28(4.40)$ & & 48 (4.79) & $3(3.40)$ \\
\hline$/ \mathrm{t} /$ & $2(2.33)$ & $5(5.25)$ & $5(4.38)$ & $81(5.27)$ & $3(3.60)$ & $66(4.96)$ & $3(3.50)$ & $4(4.30)$ \\
\hline$/ t^{\prime} /$ & $1(5.50)$ & & $4(3.29)$ & $3(4.20)$ & $19(4.26)$ & & $4(3.50)$ & \\
\hline$/ \mathrm{t}^{\mathrm{h}} /$ & $3(5.00)$ & & 84 (5.87) & & $2(4.33)$ & & $1(3.50)$ & \\
\hline$/ \mathrm{L} /$ & & $3(3.80)$ & & $3(6.50)$ & & $2(4.66)$ & & $6(4.77)$ \\
\hline$/ \mathrm{s} /$ & $1(3.00)$ & & $1(4.50)$ & & $2(4.00)$ & & $3(4.60)$ & \\
\hline$/ \mathrm{s}^{\prime} /$ & $5(2.14)$ & & $1(5.00)$ & & $28(4.00)$ & & $8(4.33)$ & \\
\hline$/ \mathrm{t} 6 /$ & & & $3(4.00)$ & & & & & \\
\hline $\begin{array}{l}\mid \mathrm{t}^{\prime} / \\
\mid \mathrm{tc}^{\mathrm{h}} /\end{array}$ & & & & & & & & \\
\hline$/ \mathrm{h} /$ & $7(5.00)$ & $1(4.00)$ & & & $1(3.00)$ & & $5(4.00)$ & \\
\hline Others & $1(5.00)$ & $3(3.50)$ & & $2(5.33)$ & & $3(4.75)$ & & $3(5.00)$ \\
\hline
\end{tabular}

Table 4. Matrix showing percentage labeling of English post-stressed intervocalic (VCV) consonants with Korean consonants and their mean goodness ratings. Judgments totaling less than 1\% are not shown. Judgments not exceeding the chance level (7.69\%) are displayed in grey. Percentages and the mean goodness ratings are rounded to the nearest whole number and to the nearest hundredth, respectively. Each stimulus had approximately 160 tokens ( 4 talkers $\times 40$ listeners) for the analysis. Similarity ratings were on a gradient scale from 1 to 7 ( 7 = exactly like Korean). Modal responses are marked in bold. 


\begin{tabular}{|c|c|c|c|c|c|c|c|c|}
\hline \multirow[b]{2}{*}{ Korean } & \multicolumn{8}{|c|}{ English consonants } \\
\hline & $/ \mathrm{p} /$ & $/ \mathrm{b} /$ & $/ \mathrm{t} /$ & $/ \mathrm{d} /$ & $/ \theta /$ & /ð/ & $/ \mathrm{f} /$ & $/ \mathrm{v} /$ \\
\hline $\begin{array}{l}/ \mathrm{p} / \\
/ \mathrm{p} /\end{array}$ & $31(4.06)$ & $49(4.22)$ & $3(6.25)$ & $11(3.76)$ & $\begin{array}{l}4(3.86) \\
3(4.40)\end{array}$ & $31(4.06)$ & $8(4.46)$ & $51(4.20)$ \\
\hline$/ \mathrm{p}^{\mathrm{h}} /$ & $24(3.70)$ & $6(3.70)$ & & $2(3.50)$ & $32(4.27)$ & $9(2.93)$ & $62(4.06)$ & $11(3.67)$ \\
\hline$/ \mathrm{t} /$ & & $6(3.20)$ & $2(4.33)$ & $41(4.33)$ & & $7(4.27)$ & 1 & $3(4.20)$ \\
\hline$/ t^{\prime} /$ & & & $3(3.50)$ & $3(5.25)$ & $3(2.40)$ & & & \\
\hline$/ \mathrm{t}^{\mathrm{h}} /$ & $3(2.40)$ & $1(4.00)$ & $73(5.26)$ & $9(4.07)$ & $3(3.75)$ & $2(3.00)$ & & $3(3.25)$ \\
\hline /L/ & $1(4.00)$ & $4(3.33)$ & & $4(4.50)$ & & $19(4.00)$ & & $4(4.57)$ \\
\hline$/ \mathrm{s} /$ & $8(3.08)$ & $6(3.88)$ & $11(3.82)$ & $16(3.96)$ & $11(3.89)$ & $4(3.00)$ & $6(4.11)$ & $4(3.00)$ \\
\hline$/ \mathrm{s} /$ & $1(4.00)$ & $1(3.00)$ & $3(4.60)$ & $1(2.00)$ & $25(4.78)$ & $3(4.00)$ & $4(4.71)$ & \\
\hline $\begin{array}{l}/ \mathrm{t} 6 / \\
/ \mathrm{t} 6^{\prime} / \\
/ \mathrm{t}^{\mathrm{h}} /\end{array}$ & & & & & & & & \\
\hline$/ \mathrm{h} /$ & $8(1.67)$ & $12(3.21)$ & $3(3.00)$ & $3(3.80)$ & $13(3.81)$ & $15(2.83)$ & $13(3.21)$ & $15(3.46)$ \\
\hline Others & $23(4.38)$ & $14(4.52)$ & $1(3.00)$ & $11(3.88)$ & $4(3.20)$ & $10(4.63)$ & $4(2.67)$ & $8(5.17)$ \\
\hline
\end{tabular}

Table 5. Matrix showing percentage labeling of English final post-vocalic (VC) consonants with Korean consonants and their mean goodness ratings. Judgments totaling less than $1 \%$ are not shown. Judgments not exceeding the chance level (7.69\%) are displayed in grey. Percentages and the mean goodness ratings are rounded to the nearest whole number and to the nearest hundredth, respectively. Each stimulus had approximately 160 tokens (4 talkers $\times 40$ listeners) for the analysis. Similarity ratings were on a gradient scale from 1 to $7(7=$ exactly like Korean). Modal responses are marked in bold. 


\begin{tabular}{|c|c|c|c|c|}
\hline \multirow[b]{3}{*}{ Korean } & \multicolumn{4}{|c|}{ English consonants } \\
\hline & \multicolumn{2}{|c|}{ Released } & \multicolumn{2}{|c|}{ Unreleased } \\
\hline & $/ \mathrm{p} /$ & $/ \mathrm{b} /$ & $/ \mathrm{p} /$ & $/ \mathrm{b} /$ \\
\hline $\begin{array}{l}/ \mathrm{p} / \\
/ \mathrm{p},\end{array}$ & $28(4.18)$ & $53(5.10)$ & $40(3.81)$ & $48(3.90)$ \\
\hline$/ \mathrm{p}^{\mathrm{h}} /$ & $23(3.59)$ & & $25(4.00)$ & $8(3.70)$ \\
\hline $\begin{array}{l}/ \mathrm{t} / \\
/ \mathrm{t}^{\prime} /\end{array}$ & & $15(3.83)$ & & $3(2.25)$ \\
\hline$/ t^{\mathrm{h}} /$ & $3(2.75)$ & & $3(1.00)$ & $2(4.00)$ \\
\hline /L/ & $2(4.00)$ & $5(3.50)$ & & $3(3.25)$ \\
\hline$/ \mathrm{s} /$ & $9(3.09)$ & & $3(3.00)$ & $8(3.89)$ \\
\hline$/ \mathrm{s}^{\prime} /$ & $2(4.00)$ & & & $2(3.00)$ \\
\hline $\mid \mathrm{t}_{6} /$ & & & & \\
\hline$/ \mathrm{t}^{\prime} /$ & & & & \\
\hline$/ \mathrm{t}^{\mathrm{h}} /$ & & & & \\
\hline$/ \mathrm{h} /$ & $7(1.50)$ & $23(2.89)$ & $10(2.00)$ & $8(3.50)$ \\
\hline Others & $23(4.33)$ & $5(3.5)$ & $20(4.60)$ & $18(4.63)$ \\
\hline
\end{tabular}

Table 6. Matrix showing percentage labeling of released and unreleased English labial stops in VC position with Korean consonants and their mean goodness ratings. Judgments totaling less than $1 \%$ are not shown. Judgments not exceeding the chance level $(7.69 \%)$ are displayed in grey. Percentages and the mean goodness ratings are rounded to the nearest whole number and to the nearest hundredth, respectively. The results are based different numbers of tokens: 40 tokens ( 1 talkers $\times 40$ listeners) for unreleased $/ \mathrm{p} /$ and released /b/, and 120 tokens (3 talkers $\times 40$ listeners) for released /p/ and unreleased $/ \mathrm{b} /$. Similarity ratings were on a gradient scale from 1 to 7 (7 = exactly like Korean). Modal responses are marked in bold. 


\begin{tabular}{|c|c|c|c|c|c|c|c|c|}
\hline \multirow[b]{2}{*}{ IPA } & \multicolumn{8}{|c|}{ English consonants } \\
\hline & $/ \mathrm{p} /$ & $/ \mathrm{b} /$ & $/ \mathrm{t} /$ & $/ \mathrm{d} /$ & $/ \theta /$ & /ठ/ & $/ \mathrm{f} /$ & $/ \mathrm{v} /$ \\
\hline$/ \mathrm{p} /$ & $76(6.07)$ & & & & & & $6(4.60)$ & $\begin{array}{l}1(4.00) \\
\end{array}$ \\
\hline$/ \mathrm{b} /$ & & $74(5.74)$ & & & $3(4.50)$ & $6(5.22)$ & & $29(4.48)$ \\
\hline$/ \mathrm{t} /$ & 4 (4.29) & & $96(6.21)$ & & & & & \\
\hline /d/ & & $4(3.83)$ & & $70(5.22)$ & & $33(5.06)$ & & $3(3.00)$ \\
\hline$/ \theta /$ & & & $1(7.00)$ & & $65(5.48)$ & $4(3.57)$ & $9(6.00)$ & $1(5.50)$ \\
\hline /ठ/ & & $4(4.14)$ & & $28(5.09)$ & $14(4.91)$ & $44(4.94)$ & $2(5.00)$ & $4(4.71)$ \\
\hline$/ \mathrm{f} /$ & $14(5.52)$ & & & & $7(4.09)$ & & $76(5.78)$ & $2(4.00)$ \\
\hline$/ \mathrm{v} /$ & & $16(5.35)$ & & & & $5(5.50)$ & $3(4.50)$ & $56(5.50)$ \\
\hline /s/ & & & & & $9(4.29)$ & & & \\
\hline $\mid \mathrm{z} /$ & & & & & & & & \\
\hline$/ 1 /$ & & & & & & $4(5.43)$ & & $1(5.00)$ \\
\hline$/ \mathrm{r} /$ & & & & & & $2(4.33)$ & & \\
\hline$/ \mathrm{j} /$ & & & & & & & & \\
\hline$/ \mathrm{w} /$ & & & & & & & & \\
\hline$/ \mathrm{h} /$ & $4(5.71)$ & & & & $2(5.00)$ & & $2(4.33)$ & \\
\hline Others & & & $1(4.50)$ & & & & & \\
\hline
\end{tabular}

Table 7. Matrix showing percentage labeling of English pre-stressed intervocalic (VCV́) consonants with Roman and IPA symbols and their mean confidence ratings. Judgments totaling less than $1 \%$ are not shown. Judgments not exceeding the chance level $(6.66 \%)$ are displayed in grey. Percentages and the mean goodness ratings are rounded to the nearest whole number and to the nearest hundredth, respectively. Each stimulus had approximately 160 tokens ( 4 talkers $\times 40$ listeners) for the analysis. Confidence ratings were on a gradient scale from 1 to $7(7=$ very confident $)$. Modal responses are marked in bold. 


\begin{tabular}{|c|c|c|c|c|c|c|c|c|}
\hline \multirow[b]{2}{*}{ IPA } & \multicolumn{8}{|c|}{ English consonants } \\
\hline & $/ \mathrm{p} /$ & $/ \mathrm{b} /$ & $/ \mathrm{t} /$ & $/ \mathrm{d} /$ & $/ \theta /$ & /ð/ & $/ \mathrm{f} /$ & $/ \mathrm{v} /$ \\
\hline$/ \mathrm{p} /$ & $33(5.19)$ & & & & $8(5.08)$ & & $14(4.59)$ & \\
\hline$/ \mathrm{b} /$ & $14(4.77)$ & $71(5.31)$ & & $8(4.67)$ & $4(4.50)$ & $15(4.79)$ & $9(4.14)$ & $50(5.00)$ \\
\hline$/ \mathrm{t} /$ & $3(4.00)$ & & $81(6.17)$ & & $4(3.14)$ & & $1(4.00)$ & \\
\hline$/ \mathrm{d} /$ & $3(4.00)$ & $3(4.00)$ & $2(4.00)$ & $53(5.25)$ & & $30(5.21)$ & $1(3.00)$ & $3(4.20)$ \\
\hline$/ \theta /$ & $4(5.43)$ & & $2(5.00)$ & $5(4.13)$ & $32(5.37)$ & $3(2.25)$ & $8(4.85)$ & $3(3.50)$ \\
\hline /ð/ & $5(4.38)$ & $4(4.14)$ & $10(4.81)$ & $28(4.89)$ & $11(4.78)$ & $38(5.20)$ & $5(4.38)$ & $4(5.00)$ \\
\hline$/ \mathrm{f} /$ & $27(4.51)$ & & $2(6.33)$ & $2(3.33)$ & $29(5.30)$ & & $42(5.67)$ & \\
\hline$/ \mathrm{v} /$ & $3(5.25)$ & $14(5.09)$ & & $2(5.00)$ & $7(4.36)$ & $10(4.94)$ & $9(5.00)$ & $33(5.40)$ \\
\hline $\begin{array}{l}/ \mathrm{s} / \\
\mid \mathrm{z} /\end{array}$ & & & $2(4.33)$ & & $3(5.50)$ & & $2(5.00)$ & \\
\hline$/ 1 /$ & & $3(5.00)$ & & & & $1(3.00)$ & & $1(3.50)$ \\
\hline$/ \mathrm{r} /$ & & & & & & & & $3(3.40)$ \\
\hline$/ \mathrm{j} /$ & & & & & & & & \\
\hline /w/ & & $1(3.50)$ & & & & & & \\
\hline$/ \mathrm{h} /$ & $3(5.40)$ & $2(4.00)$ & & & $1(5.00)$ & & $6(4.80)$ & \\
\hline Others & $4(3.00)$ & & & $1(0.50)$ & $1(2.00)$ & $1(5.50)$ & $2(2.00)$ & \\
\hline
\end{tabular}

Table 8. Matrix showing percentage labeling of English post-stressed intervocalic (VCV) consonants with Roman and IPA symbols and their mean confidence ratings. Judgments totaling less than $1 \%$ are not shown. Judgments not exceeding the chance level $(6.66 \%)$ are displayed in grey. Percentages and the mean goodness ratings are rounded to the nearest whole number and to the nearest hundredth, respectively. Each stimulus had approximately 160 tokens ( 4 talkers $\times 40$ listeners) for the analysis. Confidence ratings were on a gradient scale from 1 to $7(7=$ very confident $)$. Modal responses are marked in bold. 


\begin{tabular}{|c|c|c|c|c|c|c|c|c|}
\hline \multirow[b]{2}{*}{ IPA } & \multicolumn{8}{|c|}{ English consonants } \\
\hline & $/ \mathrm{p} /$ & $/ \mathrm{b} /$ & $/ \mathrm{t} /$ & $/ \mathrm{d} /$ & $/ \theta /$ & /ð/ & $/ \mathrm{f} /$ & $/ \mathrm{v} /$ \\
\hline$/ \mathrm{p} /$ & $22(3.71)$ & $2(3.00)$ & $5(4.13)$ & $2(2.67)$ & $2(5.67)$ & $1(3.50)$ & $4(2.86)$ & \\
\hline$/ \mathrm{b} /$ & $17(4.48)$ & $28(4.25)$ & $3(4.50)$ & $4(4.00)$ & $3(5.00)$ & $8(3.77)$ & $1(4.50)$ & $13(4.25)$ \\
\hline$/ \mathrm{t} /$ & $8(2.83)$ & $5(2.13)$ & $74(5.44)$ & $16(3.81)$ & & $6(2.67)$ & & $5(3.63)$ \\
\hline$/ \mathrm{d} /$ & $2(3.33)$ & $1(4.00)$ & & 33 (4.68) & & $5(2.75)$ & & \\
\hline$/ \theta /$ & $4(4.71)$ & $3(2.5)$ & $6(5.10)$ & $3(2.60)$ & $33(5.52)$ & $5(4.38)$ & $8(5.46)$ & $3(3.80)$ \\
\hline /ð/ & $2(5.00)$ & $2(1.33)$ & $3(4.75)$ & $6(4.70)$ & $4(3.57)$ & $2(2.67)$ & & \\
\hline$/ \mathrm{f} /$ & $10(3.50)$ & $1(5.00)$ & & & $31(4.74)$ & $13(4.95)$ & $66(5.51)$ & $20(3.94)$ \\
\hline$/ \mathrm{v} /$ & $2(3.00)$ & $14(4.26)$ & & $3(4.75)$ & & $20(5.06)$ & $4(3.57)$ & $30(4.91)$ \\
\hline$/ \mathrm{s} /$ & $1(2.50)$ & $2(4.67)$ & $1(4.50)$ & $3(2.4)$ & $11(4.44)$ & $1(2.50)$ & $2(3.00)$ & $1(3.00)$ \\
\hline$|z|$ & & & & & & & & \\
\hline$/ 1 /$ & & $2(2.33)$ & & $3(5.00)$ & & $6(3.89)$ & & $2(3.67)$ \\
\hline$/ \mathrm{r} /$ & & $3(2.75)$ & & $3(2.60)$ & & $5(4.38)$ & & $3(3.50)$ \\
\hline$/ \mathrm{j} /$ & $3(2.00)$ & $3(3.75)$ & & & & & & \\
\hline$/ \mathrm{w} /$ & $2(2.33)$ & $7(3.55)$ & & $4(2.33)$ & & $6(3.30)$ & & $10(3.88)$ \\
\hline$/ \mathrm{h} /$ & $8(2.58)$ & $8(2.75)$ & $4(3.67)$ & $5(3.25)$ & $11(4.39)$ & $14(3.35)$ & $11(4.72)$ & $10(4.31)$ \\
\hline Others & $19(1.90)$ & $21(2.65)$ & $4(2.29)$ & $14(1.50)$ & $3(1.00)$ & $8(1.75)$ & $2(0.67)$ & $3(2.60)$ \\
\hline
\end{tabular}

Table 9. Matrix showing percentage labeling of English final post-vocalic (VC) consonants with Roman and IPA symbols and their mean confidence ratings. Judgments totaling less than $1 \%$ are not shown. Judgments not exceeding the chance level $(6.66 \%)$ are displayed in grey. Percentages and the mean goodness ratings are rounded to the nearest whole number and to the nearest hundredth, respectively. Each stimulus had approximately 160 tokens ( 4 talkers $\times 40$ listeners) for the analysis. Confidence ratings were on a gradient scale from 1 to $7(7=$ very confident $)$. Modal responses are marked in bold. 


\begin{tabular}{|c|c|c|c|c|}
\hline \multirow[b]{3}{*}{ IPA } & \multicolumn{4}{|c|}{ English consonants } \\
\hline & \multicolumn{2}{|c|}{ Released } & \multicolumn{2}{|c|}{ Unreleased } \\
\hline & $/ \mathrm{p} /$ & $/ \mathrm{b} /$ & $/ \mathrm{p} /$ & $/ \mathrm{b} /$ \\
\hline$/ \mathrm{p} /$ & $23(3.68)$ & & $18(3.86)$ & $3(3.00)$ \\
\hline$/ \mathrm{b} /$ & $14(4.59)$ & $33(4.62)$ & $25(4.30)$ & $26(4.10)$ \\
\hline$/ t /$ & $8(3.00)$ & $3(2.00)$ & $5(2.00)$ & $6(2.14)$ \\
\hline$/ \mathrm{d} /$ & $3(3.33)$ & $3(7.00)$ & & $1(1.00)$ \\
\hline$/ \theta /$ & $5(4.50)$ & $3(4.00)$ & $3(6.00)$ & $3(2.00)$ \\
\hline /ठ/ & $2(5.50)$ & $3(2.00)$ & $3(4.00)$ & $2(1.00)$ \\
\hline$/ \mathrm{f} /$ & $8(3.60)$ & & $15(3.33)$ & $2(5.00)$ \\
\hline$/ \mathrm{v} /$ & $2(3.00)$ & $23(4.11)$ & $3(3.00)$ & $12(4.36)$ \\
\hline$/ \mathrm{s} /$ & $1(2.00)$ & $3(2.00)$ & $3(3.00)$ & $2(6.00)$ \\
\hline$|\mathrm{z}|$ & & & $3(7.00)$ & \\
\hline /1/ & & & & $3(2.33)$ \\
\hline$/ \mathrm{r} /$ & $1(2.00)$ & $3(3.00)$ & & $3(2.67)$ \\
\hline /j/ & $4(2.00)$ & & & $3(3.75)$ \\
\hline$/ \mathrm{w} /$ & $3(2.33)$ & $5(3.00)$ & & $8(3.67)$ \\
\hline$/ \mathrm{h} /$ & $8(3.00)$ & $5(3.00)$ & $8(1.33)$ & $8(2.70)$ \\
\hline Others & $19(3.23)$ & $20(4.00)$ & $18(5.00)$ & $22(3.44)$ \\
\hline
\end{tabular}

Table 10. Matrix showing percentage labeling of released and unreleased English labial stops in VC position with Roman and IPA symbols and their mean goodness ratings. Judgments totaling less than $1 \%$ are not shown. Judgments not exceeding the chance level $(6.66 \%)$ are displayed in grey. Percentages and the mean goodness ratings are rounded to the nearest whole number and to the nearest hundredth, respectively. The results are based different numbers of tokens: 40 tokens ( 1 talkers $\times 40$ listeners) for unreleased /p/ and released /b/, and 120 tokens ( 3 talkers $\times 40$ listeners) for released /p/ and unreleased $/ \mathrm{b} /$. Confidence ratings were on a gradient scale from 1 to 7 ( $7=$ very confident). Modal responses are marked in bold. 


\section{Figure Captions}

Figure1. Bidirectional Perceptual Mapping between English and Korean categories in VCV́ context. The width of each line in English to Korean categories corresponds to the proportion of times the Korean label was applied to the English production. The width of each line in Korean to English categories corresponds to the proportion of the English productions which bore the Korean label. Connections directly relevant to correct identification of English sounds are shown. Any connections less than $7.69 \%$ are not included.

Figure 2. Accuracy Rate Predictions in VCV́ context. Accuracy in labeling English productions with Roman/IPA symbols plotted as a function of the accuracy predicted from labeling with Korean orthographic labels. Empty circles represent stops and filled circles indicate fricatives. The line $(x=y)$ indicates exact prediction by the model. The left panel (a) plots predictions from a model without weighting by goodness ratings, while the right panel (b) plots weighted predictions.

Figure 3. Bidirectional Perceptual Mapping between English and Korean categories in V́CV context. The width of each line in English to Korean categories corresponds to the proportion of times the Korean label was applied to the English production. The width of each line in Korean to English categories corresponds to the proportion of the English productions which bore the Korean label. Connections directly relevant to correct identification of English sounds are shown. Any connections less than 7.69\% are not included.

Figure 4. Accuracy Rate Predictions in V́CV context. Accuracy in labeling English productions with Roman/IPA symbols plotted as a function of the accuracy predicted from labeling with Korean orthographic labels. Empty circles represent stops and filled circles indicate fricatives. The line $(x=y)$ indicates exact prediction by the model. The left panel (a) plots predictions from a model without weighting by goodness ratings, while the right panel (b) plots weighted predictions.

Figure 5. Bidirectional Perceptual Mapping between English and Korean categories in VC position. The width of each line in English to Korean categories corresponds to the proportion of times the Korean label was applied to the English production. The width of each line in Korean to English categories corresponds to the proportion of the English productions which bore the Korean label. Connections directly relevant to correct identification of English sounds are shown. Any connections less than $7.69 \%$ are not included.

Figure 6. Accuracy Rate Predictions for the entire corpus in VC position. Accuracy in labeling English productions with Roman/IPA symbols plotted as a function of the accuracy predicted from labeling with Korean orthographic labels. Empty circles represent stops and filled circles indicate fricatives. The line $(x=y)$ indicates exact prediction by the model. The left panel (a) plots predictions from a model without weighting by goodness ratings, while the right panel (b) plots weighted predictions.

Figure 7. Accuracy Rate Predictions for the labial stops in VC position. Accuracy in labeling English productions with Roman/IPA symbols plotted as a function of the accuracy predicted from labeling with Korean orthographic labels. Empty and filled symbols represent voiceless voiced stops, respectively. Diamond and triangle symbols indicate released and unreleased labial stops, respectively. Circles are the labial stops combining both released and unreleased instances. The line $(x=y)$ indicates exact prediction by the model. The left panel (a) plots 
predictions from a model without weighting by goodness ratings, while the right panel (b) plots weighted predictions. 


\section{Figures}

Figure 1

English stimulus Korean Category English response

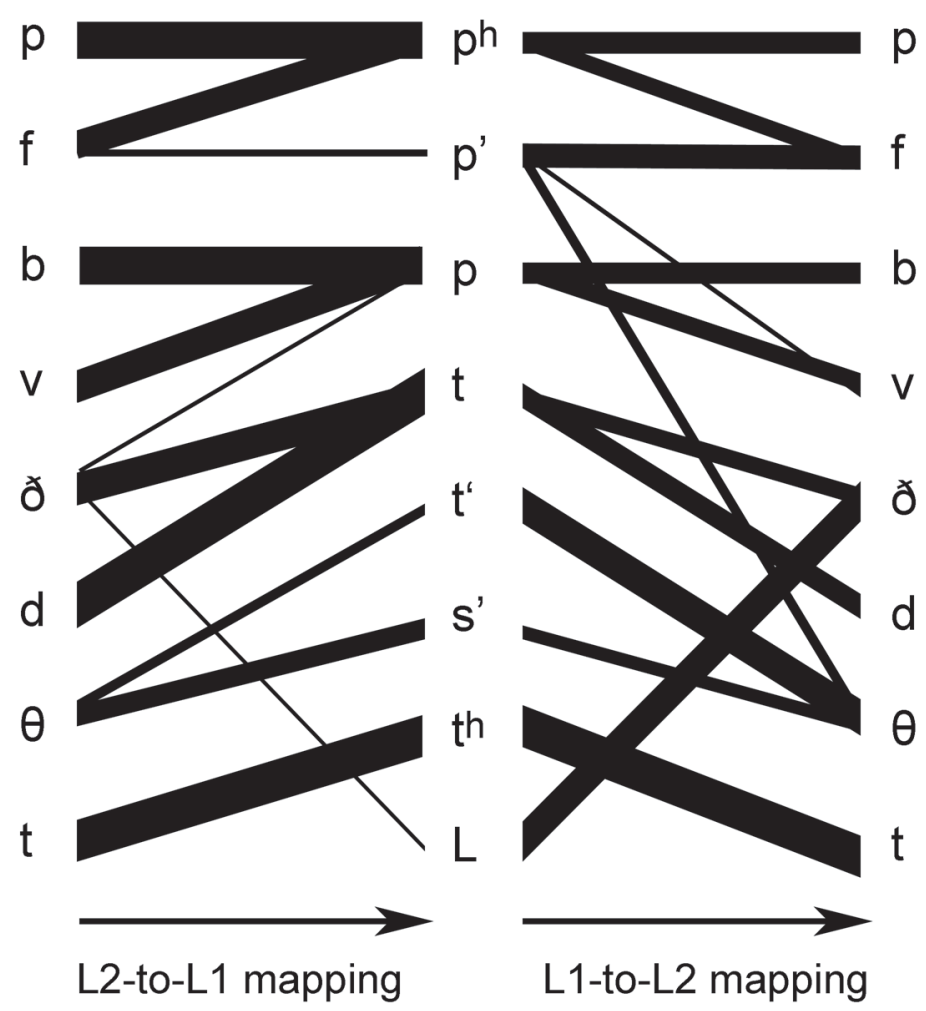


Figure 2

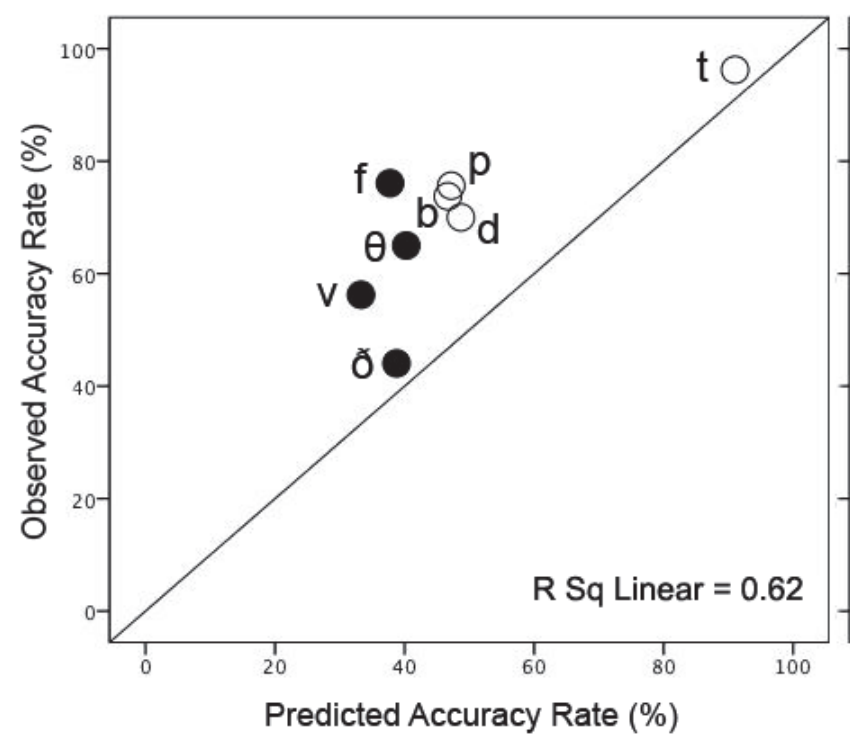

(a) Unweighted model

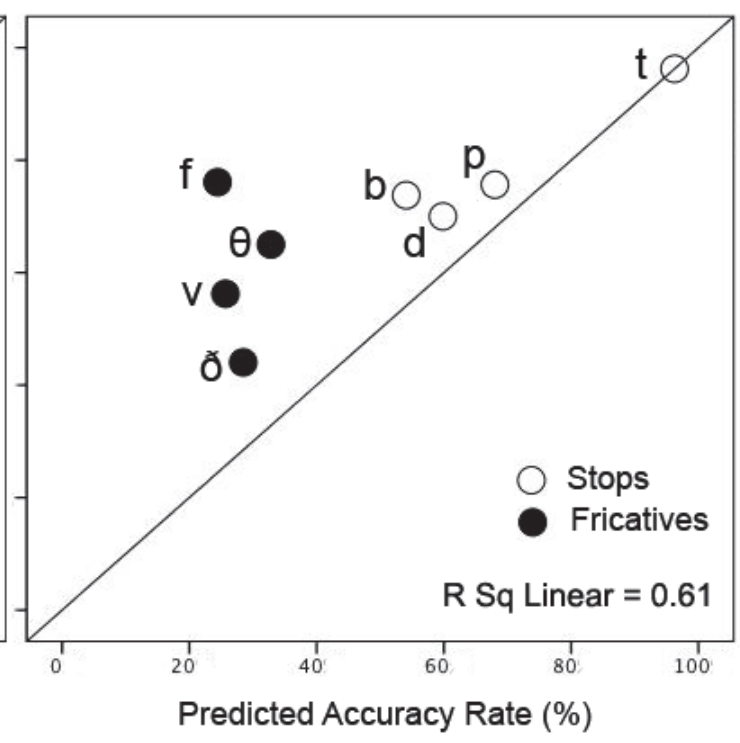

(b) Weighted model 
Figure 3

English stimulus Korean Category English response

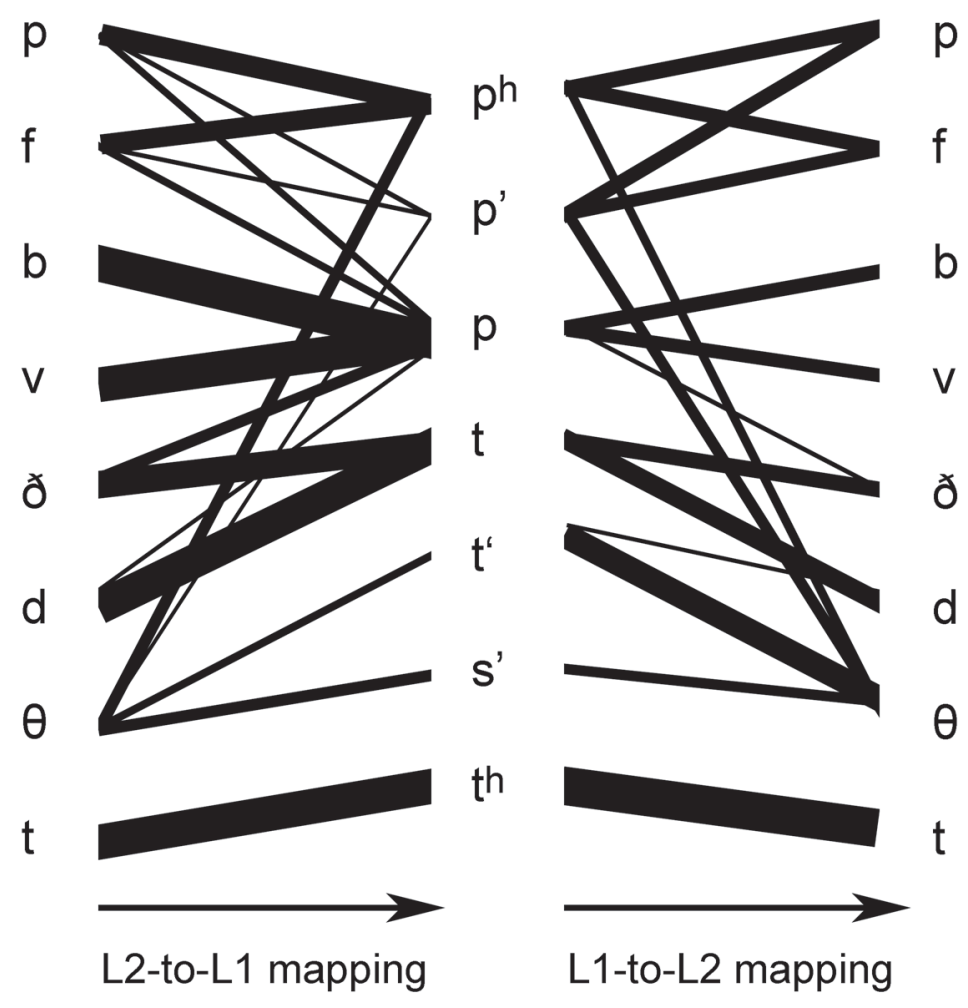


Figure 4

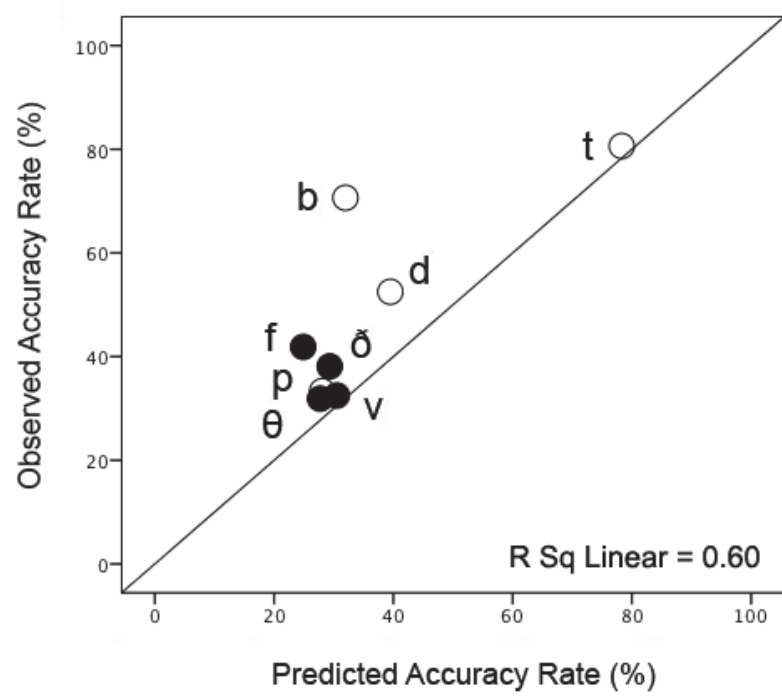

(a) Unweighted model

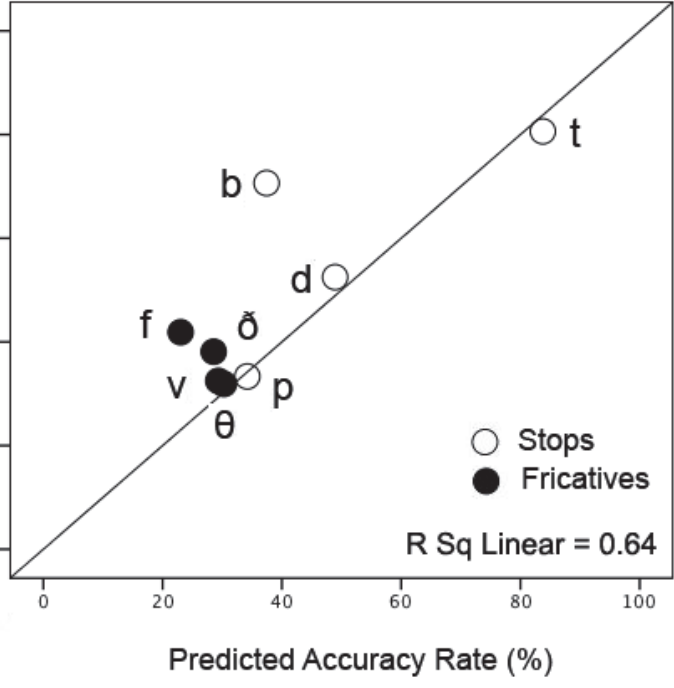

(b) Weighted model 
Figure 5

English stimulus Korean Category English response

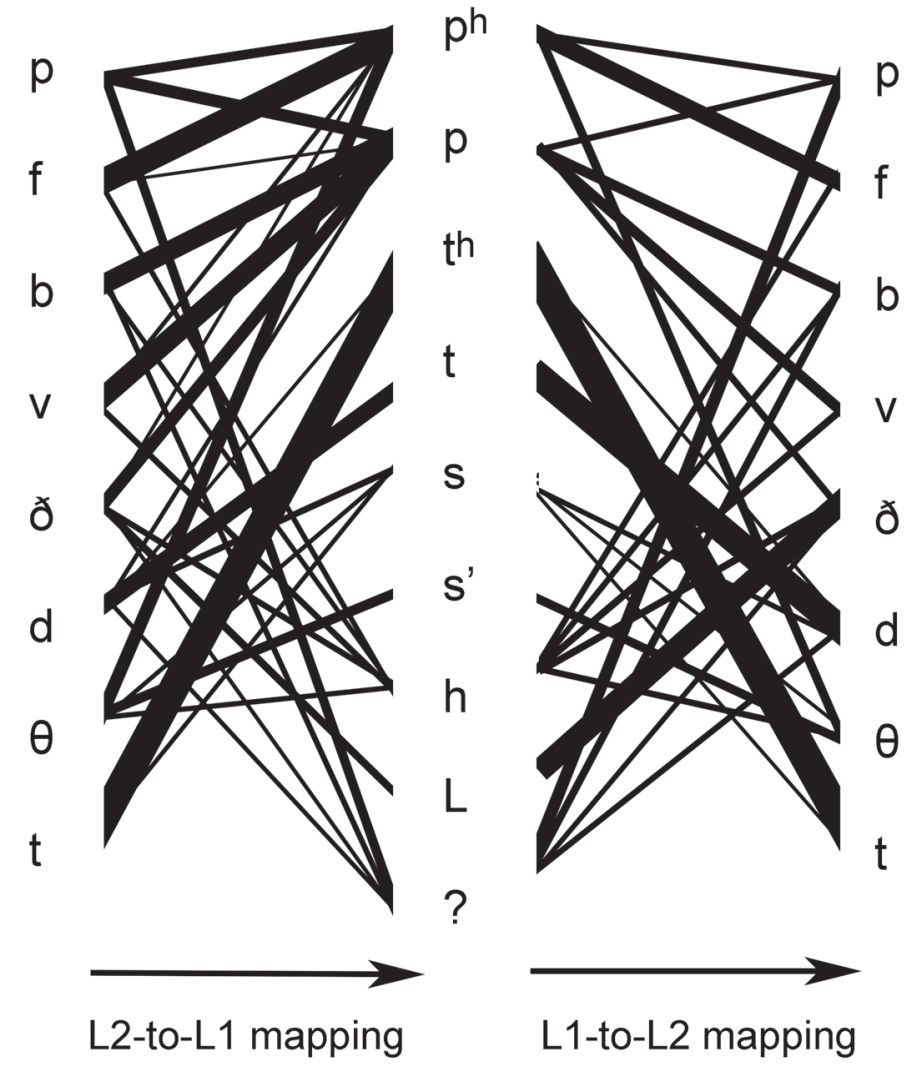


Figure 6

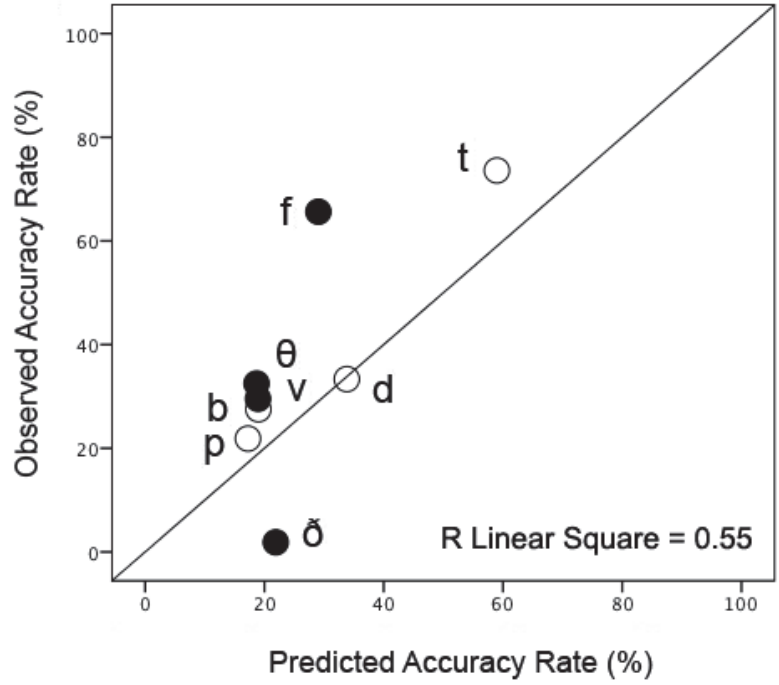

(a) Unweighted model

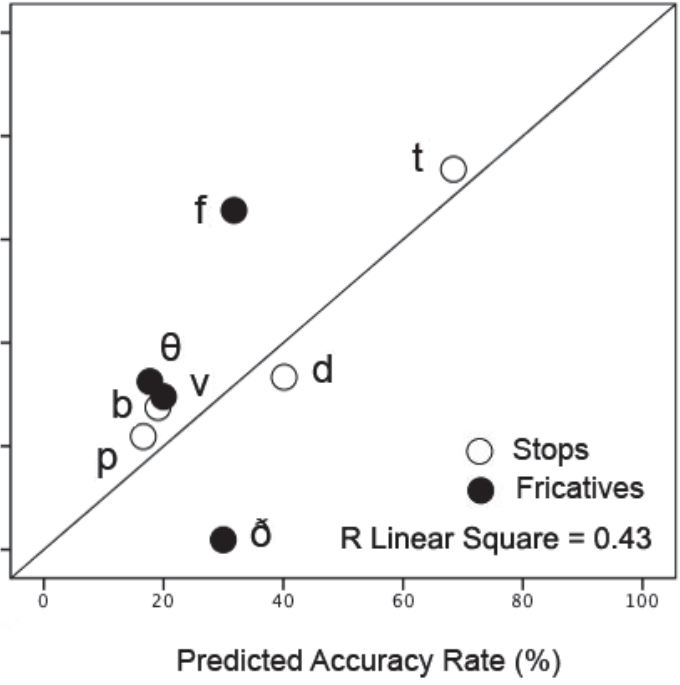

(b) Weighted model 
Figure 7

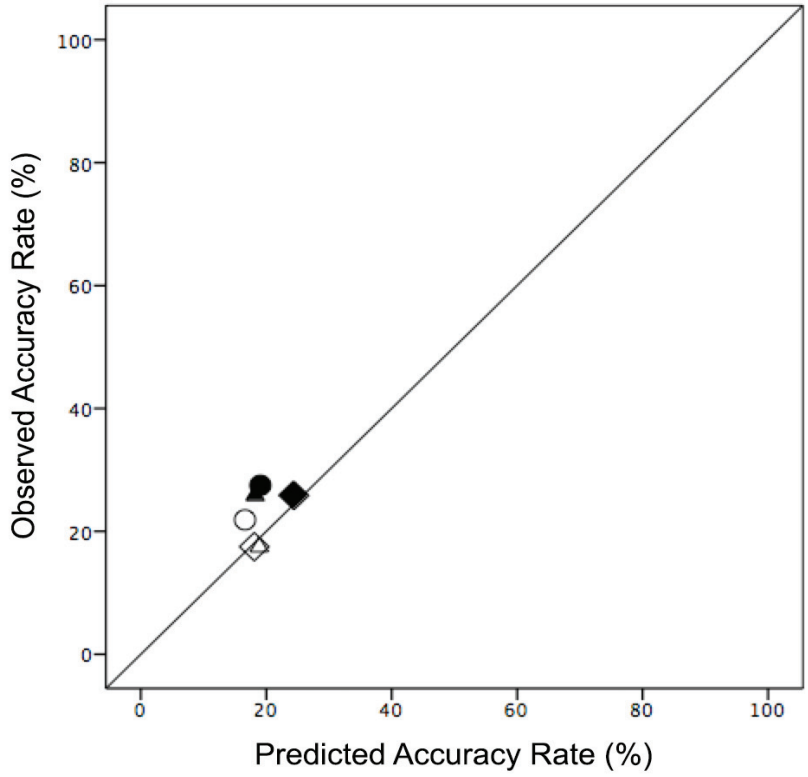

(a) Unweighted model

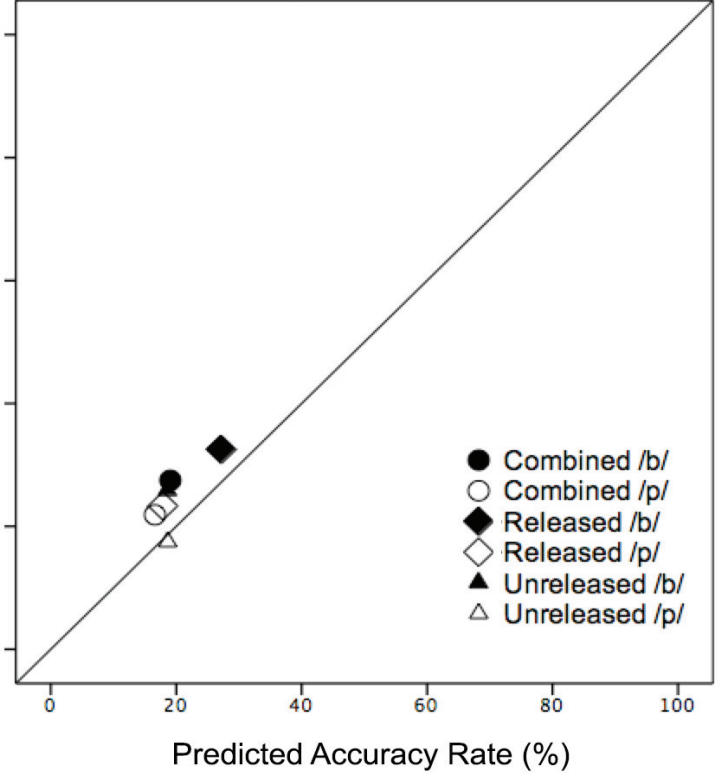

(b) Weighted model 